NASA Technical Memorandum 87347

AIAA-86-1438

\title{
The Noncavitating Performance and Life of a Small Vane-Type Positive Displacement Pump in Liquid Hydrogen
}

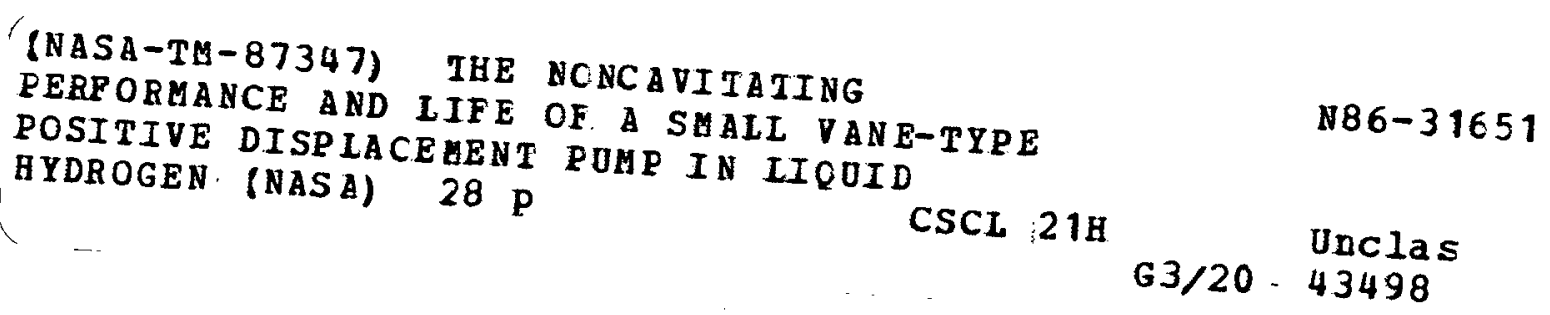

$63 / 20-43498$

Thomas E. Ulbricht and Joseph A. Hemminger

Lewis Research Center

Cleveland, Ohio

Prepared for the

22nd Joint Propulsion Conference

cosponsored by the AIAA, ASME, SAE, and ASEE

Huntsville, Alabama, June 16-18, 1986 
THE NONCAVITATING PERFORMANCE AND LIFE OF A SMALL VANE-TYPE

POSITIVE DISPLACEMENT PUMP IN LIQUID HYDROGEN

Thomas E. Ulbricht and Joseph A. Heminger

National Aeronautics and Space Administration

Lewis Research Center

Cleveland, Ohio 44135

\section{SUMMARY}

The low flow rate and high head rise requirements of hydrogen/oxygen auxiliary propulsion systems make the application of centrifugal pumps difficult. Positive displacement pumps are well-suited for these flow conditions, but little is known about their performance and life characteristics in liquid hydrogen. An experimental and analytical investigation was conducted to determine the performance and life characteristics of a vane-type, positive displacement pump. In the experimental part of this effort, mass flow rate and shaft torque were determined as functions of shaft speed and pump pressure rise. Since liquid hydrogen offers little lubrication in a rubbing situation, pump life is an issue. During the life test, the pump was operated intermittently for $10 \mathrm{hr}$ at the steady state point of $0.0741 \mathrm{bm} / \mathrm{sec}(0.03 \mathrm{~kg} / \mathrm{sec}) \mathrm{flow}$ rate, 300 psid (2.07 $\mathrm{MPa})$ pressure rise, and $8000 \mathrm{rpm}(838 \mathrm{rad} / \mathrm{sec}$ ) shaft speed. Pump performance was monitored during the life test series and the results indicated no loss in performance. Material loss from the vanes was recorded and wear of the other components was documented. In the analytical part of this effort, a comprehensive pump performance analys is computer code, developed in-house, was used to predict pump performance. In this paper, the results of the experimental investigation will be presented and compared with the results of the analysis. Results of the life test will also be presented.

\section{INTRODUCTION}

Liquid hydrogen $\left(\mathrm{LH}_{2}\right)$ - liquid oxygen $\left(\mathrm{LO}_{2}\right)$ auxiliary propulsion systems require efficient propeliant feed pumps to produce high chamber pressure at a low flow rate. These flow requirements make the application of dynamic pumps difficult because of their low efficiency at these conditions.

The positive displacement pump is a logical choice for this application (ref. 1) and the vane-type, positive displacement pump (or vane pump) is a good candidate. The vane pump has a good overall pump efficiency, is lightweight, and has small bearing loads when dual-lobed configurations are employed. However, there is almost no experience with this type of pump in the cryogenic environment (ref: 1).

The purpose of the work reported here is to provide performance data in $\mathrm{LH}_{2}$ on a vane pump representative of the size required for an auxiliary propulsion system. Experimental data on the overall performance of a vane pump is presented. A model for predicting pump performance is also presented with its results being compared to the experimental data. 
NOMENCLATURE

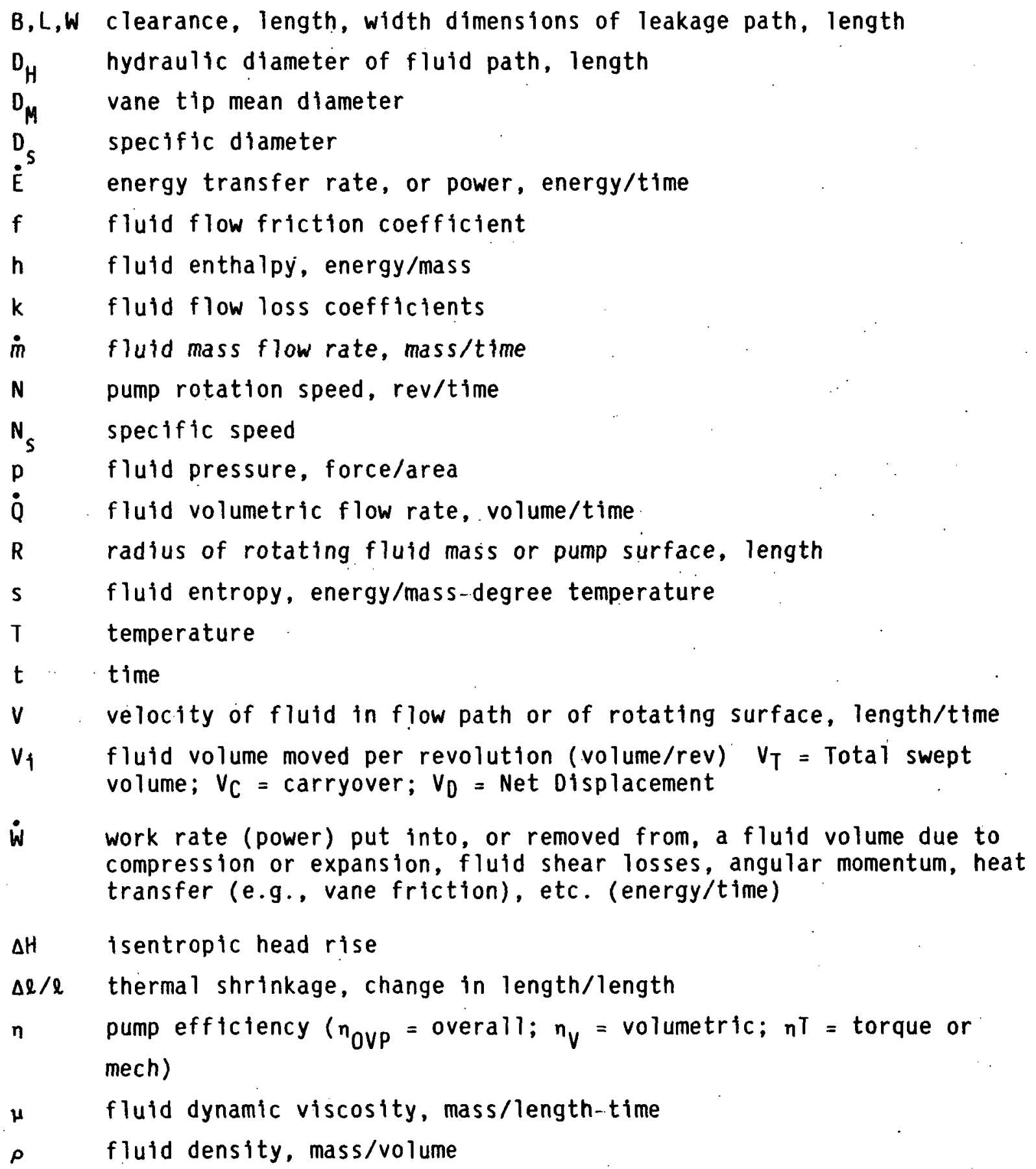

APPARATUS ANO METHOOS

Details of the vane pump design, test rig configuration, instrumentation and test procedures will be discussed in this section. 
The goals of the vane pump design were:

Speed, $\mathrm{rpm}(\mathrm{rad} / \mathrm{sec})$..................... . 8000 (838)

Pressure rise, psid (MPa) .................. $216(1.49)$

Delivered flow rate, $\mathrm{gpm}\left(\mathrm{M}^{3} / \mathrm{sec}\right)$............. $7.8\left(4.9 \times 10^{-4}\right)$

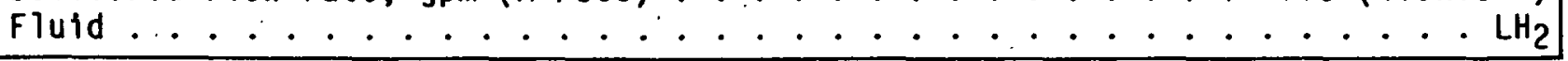

Complete details of the vane pump design are given in reference 2 .

An exploded view of the important pump hardware is shown in figure 1. The pump design features a dual-lobed, 7 th degree polynominal cam profile as the liner bore. The dual-lobed construction produces a radial pressure balance on the rotor, thus minimizing radial bearing loads. The cam proflle was chosen in order to provide a good balance between maximum and minimum vane acceleration and vane jerk (i.e., time rate of change of acceleration).

The number of vanes was chosen to be 16. This feature insures that at least two vanes are positioned between the discharge and suction ports at any time during the rotor cycle. This, in effect, halves the internal leakage between these ports.

Kidney ports, located in the port plates (see fig. 1), provide inlet and discharge pressure to the undervane volumes (see fig. 2). The kidney ports are timed with respect to the suction and discharge ports such that during most of the rotor cycle, the radial pressure loading on each vane is balanced. The exception to this occurs $1^{\circ}$ prior to, and $1^{\circ}$ after, the vane tip sees full discharge pressure. During this time, the vane tip is at inlet pressure and the undervane pressure is equal to the full discharge pressure, thus producing a net radial pressure loading on the vane. This radial pressure loading, along with centrifugal force, seats the vane against the liner and reduces vane tip leakage during this part of the rotor cycle.

Major pump dimensions are given at room temperature in Table I. Since the rotor and liner are both made from the same material, the rotor/port plate clearance will not change at cryogenic temperatures. An exaggerated view of the important pump clearances are shown in figure 3 . A negative clearance between the rotor and vanes is given in Table $I$. The excess vane length is required to compensate for the difference in thermal shrinkage rates betwcen the liner and rotor material (440C) and the vane material (B-8). This difference, where

$$
\left(\frac{\Delta l}{\ell}\right)_{\text {vanes }}>\left(\frac{\Delta \ell}{\ell}\right)_{\text {iiner, rotor }}
$$

tends to increase the clearance between the vanes and the port plates, thus increasing the amount of internal leakage around the sides of the vanes. To compensate for this, the spring loaded port plate, which is free to move axially (see fig. 3), is spring loaded by a static seal against the cam liner. This allows the pump to be assembled at room temperature with an interference fit between the vanes and the port plate without damage to the pump. 
The proper choice of materials is crucial for a successful cryogenic vane pump design. Materials for the design reported here were chosen on the basis of mechanical properties at cryogenic temperatures and wear resistance. For good wear resistance, a soft-on-hard material combination was selected. The soft material selected was leaded bronze. The grade, B-8, has a chemical composition of 70 percent $\mathrm{Cu}, 8$ percent $\mathrm{Sn}$, and 22 percent $\mathrm{Pb}$. This material is commonly used for bearing surfaces that are required to operate with little or no lubrication. The lead is dispersed throughout the material in small particles, and gives the material a self-lubricating quality. The vanes and port plates are constructed from this material. The hard material, AISI 440C stainless steel, is used for the rotor and liner. The material is heat-treated to produce a Rockwell hardness of about 660 .

\section{Test Rig}

The vane pump, pump drive, and drive motor with torque meter are shown as an assembly in figure 4 . The pump and pump drive assembly is mounted in the side of the run tank allowing the vane pump to be fully submerged in $\mathrm{LH}_{2}$ during the testing. The pump drive assembly consists of the mounting flanges, a drive shaft and its bearings, and a buffer seal. The buffer seal is of the labyrinth type and introduces negligible tare torque into the system. The pump is driven by a small (10 hp) gear-type, hydraulic motor. The pump drive is connected to the hydraulic motor through a noncontacting, strain gage torque meter instrumented with a magnetic speed sensor. The torque meter is coupled to the hydraulic motor and pump drive by flexible couplings.

A schematic of the pump test rig plumbing and instrumentation is shown in figure 5. The system consists of a run tank, tank pressurization and venting system, and discharge plumbing. The run tank is a 300 gal (1135 liter), vacuum jacketed dewar with a large flange in its side for mounting the pump and drive assembly (see fig. 6). The run tank can be pressurized up to $60 \mathrm{psia}(414 \mathrm{kPa})$ with gaseous helium (GHe) or vented to 1 to 2 psig $(6.9$ to $13.8 \mathrm{kPa}$ ). Pumped fluid is routed through an insulated line out of the run tank, through a venturi flowmeter and the discharge pressure control valve, and then either returned to the run tank, rerouted to a roadable dewar, or vented to the atmosphere. The system is capable of handling liquid nitrogen and liquid oxygen, as well as liquid hydrogen.

The rig is instrumented to measure inlet and discharge temperatures and pressures, delivered mass flow rate, shaft torque, and shaft speed. The delivered mass flow rate is measured using a venturi flowmeter. The venturi is instrumented for temperature and pressure measurement so that local density may be determined. All of the temperature sensors in the rig are of the platinum resistance type. The pressure transducers are of the strain-gaged, diaphragm type.

\section{Test Methods}

The test serles consisted of noncavitating pump performance tests and pump $11 \mathrm{fe}$ tests. The objectives of the performance tests were to determine (as a function of pressure rise across the pump and pump speed) the delivered flow 
rate, power consumption, overall pump efficiency, torque or mechanical efficlency, and volumetric efficlency. These data were then used to verify the pump performance model. The purpose of the life test series was to show that the pump had a useful operating life of at least $10 \mathrm{hr}$ in $\mathrm{LH}_{2}$.

To insure noncavitating conditions in the pump, the inlet fluid was subcooled in the range of 5.6 to $7.7^{\circ} \mathrm{R}(3.1$ to $4.3 \mathrm{~K}$ ) during the performance tests. This was accomplished by allowing the fluid in the vented run tank to cool to about $38^{\circ} \mathrm{R}(21 \mathrm{~K}$ ) and then pressurizing the tank to 45 to 51 psia (337 to $352 \mathrm{kPa}$ ) and maintaining it at this pressure during the tests.

For the performance tests, the pump speed was held constant and pump pressure rise was varied from zero to $350 \mathrm{psid}(2.41 \mathrm{MPa})$ by varying the discharge pressure with the discharge pressure control valve. Performance was measured at three pump speeds, 8000,6000 , and $4000 \mathrm{rpm}(838,628$, and $419 \mathrm{rad} / \mathrm{sec})$. The discharged pump fluid was vented to the atmosphere so that zero pump pressure rise could be achieved.

Vane pump life tests were conducted at a pump speed of $8000 \mathrm{rpm}$ (838 rad/sec) and a pressure rise of $300 \mathrm{psid}(2.07 \mathrm{MPa})$. Suction conditions were established in the same manner as the performance tests. The duration of each life test segment was limited by the onset of cavitation due to the warming (from external heat leaks) of the $\mathrm{LH}_{2}$ in the run tank. The typical length of a life test segment was $20 \mathrm{~min}$. Life tests were continued until $10 \mathrm{hr}$ of steady-state operation had accumulated on the pump.

\section{PUMP PERFORMANCE ANALYSIS}

The following description of the vane pump performance model was first reported by the authors in reference 3 and is repeated here for completeness.

PUMP FLOW MODEL

The flow model on which the vane pump analysis code is based is 1llustrated in figure 7: Fluid mass and energy flow continuity and conservation are assumed in the model. In the following presentation, single subscripts (e.g., $\left.h_{j}\right)$ refer to properties of the fluid at the "nodes" in figure 7 . Dual subscripts refer either to average properties of the fluid along a fluid path (e.g.. $\left.p_{i j}=\left(p_{j}+p_{j}\right) / 2\right)$ or to activity on or by the fluid along a fluid path (e.g., wif is the work done on the fluid as it moves from point $\{$ to point $j$ ).

\section{Pump Mass Flow}

The equations defining mass flow can be summarized as follows (see Nomenc lature for definition of terms):

$$
\begin{aligned}
\dot{\mathrm{m}}_{4 I D E A L} & =\dot{m}_{6 \text { IDEAL }}=\rho_{4} V_{D} N=\rho_{4}\left(V_{T}-V_{C}\right) \mathrm{N} \quad \text { (IDEAL MASS FLOW) } \\
& =\dot{\mathrm{m}}_{9 \text { IDEAL }}-\dot{\mathrm{m}}_{8 I D E A L}
\end{aligned}
$$




$$
\begin{aligned}
& \underbrace{\dot{m}_{9}=\dot{m}_{4}+\dot{m}_{7}+\dot{m}_{8}}_{\text {INLET ZONE }}=\underbrace{\dot{m}_{6}+\dot{m}_{11}+\dot{m}_{7}+\dot{m}_{8}}_{\text {DISCHARGE ZONE }} \\
& \underbrace{\dot{m}_{4}}_{\text {INLET }}=\underbrace{\dot{m}_{6}+\dot{m}_{11}}_{\text {DISCHARGE }} \text { (TOTAL MASS FLOW) } \\
& \text { (NET MASS FLOW) }
\end{aligned}
$$

\section{Pump Energy, Flow}

The equations defining energy flow through the pump are summarized as follows:

$$
\begin{aligned}
& \left.\begin{array}{l}
\dot{E}_{\text {DISCHARGE }}=\dot{E}_{\text {INLET }}+\dot{w}_{\text {DONE ON OR BY FLUID }} \\
\dot{m} n_{\text {out }}=\dot{m} n_{\text {in }}+\dot{w}
\end{array}\right\} \\
& \dot{w}_{\text {COMP OR EXP }}=\left(\frac{\dot{m}}{\rho_{A V G}}\right) \times\left(p_{O U T}-p_{I N}\right) \quad \text { (ISENTROPIC }=\text { IDEAL) } \\
& \dot{m}_{7} h_{7}=\dot{m}_{7} h_{6}+\dot{w}_{67} \\
& \text { (INTERNAL LEAKAGE) } \\
& \dot{m}_{8} h_{8}=\dot{m}_{8} h_{6}+\left(\dot{w}_{68}-\dot{W}_{E X P 89}\right) \quad \text { (CARRYOVER LEAKAGE) } \\
& \dot{m}_{11} h_{11}=\dot{m}_{11} h_{6}+\dot{w}_{611} \quad \text { (EXTERNAL LEAKAGE) } \\
& \dot{m}_{9} h_{9}=\dot{m}_{4} h_{4}+\dot{m}_{7} h_{7}+\dot{m}_{8} \dot{h}_{8} \quad \text { (INLET TOTAL FLOW) } \\
& \dot{m}_{9} h_{6}=\left(\dot{m}_{6}+\dot{m}_{11}+\dot{m}_{7}+\dot{m}_{8}\right) h_{6} \quad \text { (OISCHARGE TOTAL FLOW) } \\
& =\dot{m}_{9} h_{9}+\dot{w}_{\text {COMPg6 }}+\dot{w}_{\text {VANE FRICTION }} \\
& \dot{w}_{\text {IDEAL }}=\frac{\dot{m}_{6 I D E A L}}{\rho_{46}} \times\left(p_{6}-p_{4}\right)
\end{aligned}
$$




$$
\left.\begin{array}{rl}
\dot{w}_{\text {ACTUAL }} & =\dot{w}_{\text {COMP96 }}+\dot{w}_{67}+\left(\dot{w}_{68}-\dot{w}_{\text {EXP89 }}\right)+\dot{w}_{611}+\dot{w}_{\text {VANE }} \\
& =\dot{m}_{6} n_{6}+\dot{m}_{11} n_{11}-\dot{m}_{4} n_{4}
\end{array}\right\} \begin{aligned}
& \begin{array}{l}
\text { (SHATION } \\
\text { INPUT } \\
\text { POWER) }
\end{array} \\
&
\end{aligned}
$$

LEAKAGE FLOW MODEL

Mass flow and energy losses are calculated for leakage paths according to the model illustrated in figure 8. Because of the small pump clearances, the model assumes laminar flow between closely-spaced flat plates. There are three possible forces that drive the flow in a leakage path:

(1) Pressure differential between the connected volumes;

(2) Centrifugal (or body) force on the fluid due to rotation;

(3) Shear between moving pump parts.

\section{Leakage Mass Flow}

The total pressure drop through a leakage path is:

$$
\begin{aligned}
\Delta p_{\text {TOTAL }} & =\Delta p_{\text {CONTR }}+\Delta p_{E N T}+\Delta p_{F R I C}+\Delta p_{E X P} \\
= & {\left[k_{\text {CONTR }} \frac{e v^{2}}{2}\right]+\left[\left(f \frac{L_{e}}{D_{H}}+k_{E N T}\right) \frac{e v^{2}}{2}\right]+\left[\frac{f\left(L-L_{e}\right)}{D_{H}} \cdot \frac{\rho v^{2}}{2}\right]+\left[k_{E X P} \frac{e v^{2}}{2}\right] . }
\end{aligned}
$$

The contribution of fluid body, or centrifugal, force to the leakage (applicable when the flow direction is radial) is handled by converting it to an equivalent pressure term PCENT and algebraically summing it to the delta pressure between the connected volumes.

$$
\triangle P_{T O T A L}=\Delta \text { PPRESS }+P_{C E N T}=\left(P_{I N}-P_{O U T}\right)+\rho L R_{A V G} \pi^{2} N^{2}
$$

Substituting in equation (14) for the hydraulic diameter $\left(D_{H}=28\right.$ where $B<W$ ), velocity $(V=Q / B W)$, and friction coefficient ( $f=96 / R e=96 \mu / V D_{H} \rho$ for laminar flow between two flat plates) yields the following equation from which the volumetric flow rate $Q$ can be solved directly.

$$
\left[\frac{\left(k_{\text {CONTR }}+k_{E N T}+k_{E X P}\right) p}{2 B^{2} W^{2}}\right] Q^{2}+\left[\frac{12 L \mu}{B^{3} W}\right] \&-\Delta P_{\text {TOTAL }}=0
$$

The following values have been assumed for the loss coefficients $K_{\text {CONTR }}=0.5 ; K_{E N T}=0.69 ; K_{E X P}=1.0$ (ref. 4 ). If turbulent conditions exist in the leakage path, the friction coefficient is not a linear function of flow rate, requiring an iterative approach to solving the flow equation.

There is also a contribution to the flow due to shear between moving surfaces in the pump. This flow can be determined as follows: 


$$
\dot{Q}_{\text {SHEAR }}=\left(V_{A V G}\right)(\text { AREA })=\left(\frac{V_{\text {SURF }}}{2}\right)(B W)=\left(2 \pi R \text { AVG } \frac{N}{2}\right)(B W)=\pi R_{A V G}{ }^{N B W}
$$

The net mass flow rate is determined from the algebraic sum of the $\triangle P_{\text {TOTAL }}$ and shear volumetric flow rates as follows:

$$
\dot{m}_{\text {LEAKAGE }}=\rho_{\text {AVG }}\left(\dot{\mathrm{Q}}_{\triangle P}+\dot{\mathrm{Q}}_{\text {SHEAR }}\right)
$$

\section{Leakage Energy flow}

The fluid moving in leakage paths bounded by moving surfaces either enhance or retard the motion of the parts, thereby affecting the net energy balance of the pump. The same forces which drive the flow also affect the energy balance. The energy loss (or gain) contributed by the moving fluid to the pump surface can be separated into two components:

(1) $\Delta p$ friction and form losses, and (2) fluid shear losses. The $\Delta p$ component is

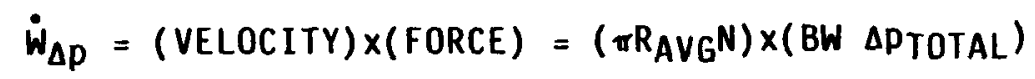

The fluid shear component is

$$
\dot{\mathrm{W}}_{\text {SHEAR }}=\left(2 \pi \mathrm{R}_{A V G}\right)^{2}{ }^{2} \mathrm{LL} \frac{\mathrm{W}}{\mathrm{B}}
$$

The net energy gain or loss by the fluid is

$$
\dot{w}_{\text {LEAKAGE }}=\dot{w}_{\triangle P}+\dot{w}_{S H E A R}
$$

\section{LEAKAGE FLOW TYPES}

Fluid leakage in the vane pump decreases its volumetric efficiency. There are three types of leakage in a vane pump.

\section{Carryover Leakage}

This leakage represents the fluid that is swept from the high-pressure discharge to the low-pressure inlet due to the clearances between: (1) the rotor and the cam liner minor diameter; (2) the inside (or undervane) edge of the vane and the bottom of the rotor vane slot. The carryover mass flow rate is:

$$
\dot{m}_{8}=p_{6} V_{c} N \quad \text { where } V_{c}=16\left(V_{c i}+V_{c u}\right)
$$

Its effect on volumetric efficiency is more significant when the pumped fluid is compressible (as is the case with $\mathrm{LH}_{2}$ ) because the higher density of the high-pressure discharge fluid results in a higher carryover mass flow rate than would be the case for an incompressible fluid. Energy $\dot{W}_{68}$ is added to this fluid due to fluid shear between the rotor and cam liner surfaces. The fluid also returns power $\dot{W}_{\text {EXPBg }}$ to the input shaft as it expands from discharge to inlet pressure. A schematic of the pump volumes is shown in figure 2. 
This leakage is the sum of all fluid flow through leakage paths in the pump that returns to the inlet of the pump. The internal leakage paths that are included in the vane pump model include paths between:

(1) Vane tip and cam liner (connects intervane volumes);

(2) Vane side edges and side port plates (connects intervane volumes);

(3) Vane and rotor slot faces (connects intervane and undervane volumes);

(4) Rotor ends and side port plates (connects intervane volumes);

(5) Rotor ends and side port plates (connects high-pressure and lowpressure kidney-shaped ports in port plates).

The net sum of all these flows is $\dot{m}_{7}$. The net sum of fluid energy gain due to friction and shear is $\dot{W}_{67}$.

\section{External Leakage}

This leakage is the sum of all fluid flow through leakage paths in the pump that exit to volumes other than the pump inlet. The external leakage path included in the vane pump model is between the rotor ends and side port plates, connecting the high-pressure kidney ports to the volume enclosing the rotating shaft. The net sum of these flows is $\dot{m}_{71}$. The net fluid energy gain due to friction and shear is $\dot{\omega}_{611}$.

\section{VANE FORCE MODEL}

A vane force model was developed in order to determine the vane friction losses. The vane friction energy is assumed to be input directly into the bulk pump fluid (see eq. (13)). Vane rubbing friction is a linear function of the assumed coefficient of friction between the rubbing surfaces. Because the vane friction energy term is significant, and the coefficient value has not been verified in separate testing, there is this built-in uncertainty in the performance predictions.

\section{PUMP EFFICIENCY}

Overall vane pump efficiency is a product of its: (1) volumetric efficiency, and (2) torque (or mechanical) efficiency. Volumetric efficiency reflects the loss in output flow rate due to leakage (internal, external, and carryover) and is determined as follows:

$$
n_{V}=\frac{\dot{m}_{6 A C T U A L}}{\dot{m}_{6 \text { IDEAL }}}=\frac{\dot{m}_{9}-\dot{m}_{7}-\dot{m}_{8}-\dot{m}_{11}}{\rho_{4} V_{D}^{N}}=\frac{\text { ACTUAL FLOW RATE }}{\text { IDEAL FLOW RATE }}
$$


Torque (or mechanical) efficiency reflects energy losses, primarily resulting from vane rubbing friction and leakage fluid shear. It is determined as follows:

$$
n_{T}=\frac{\dot{w}_{\text {IDEAL }}}{\dot{w}_{\text {ACTUAL }}}=\frac{\left(\frac{\dot{m}_{6 I O E A L}}{p_{46}}\right) \times\left(p_{6}-p_{4}\right)}{\sum \dot{w}=\sum(\dot{m} h) \text { in \& out }}=\frac{\text { IDEAL HYD. OUTPUT POWER }}{\text { ACTUAL SHAFT INPUT POWER }}
$$

The product yields the overall pump efficiency

$$
n_{\text {OVP }}=n_{V} \times n_{T}=\frac{\left(\frac{\dot{m}_{\text {GACTUAL }}}{p_{46}}\right) \times\left(p_{6}-p_{4}\right)}{\dot{w}_{\text {ACTUAL }}}=\frac{\text { HYORAULIC OUTPUT POWER }}{\text { SHAFT INPUT POWER }}
$$

\section{DISCUSSION OF RESULTS}

Theoretical and experimental results for pump delivered volumetric flow rate and power consumption are compared in figures 9 and 10 . Experimental results for delivered mass flow rate versus pump speed and pump efficiencies versus pressure rise are shown in figures 11 to 14 . At the design point of $8000 \mathrm{rpm}(838 \mathrm{rad} / \mathrm{sec})$ pump speed, and $216 \mathrm{psid}(1.49 \mathrm{MPa})$ pressure rise, the flow rate was $7.7 \mathrm{gpm}\left(4.86 \times 10^{-4} \mathrm{~m} / \mathrm{sec}\right)$ and the overall pump effictency was 49 percent. Table II gives a summary of the experimental pump performance at the design point. Specific speed, $N_{S}$, and specific diameter, $D_{S}$ are defined by:

$$
\begin{array}{r}
N_{S}=\frac{N(\dot{Q})^{0.5}}{(\Delta H)^{0.75}} \\
D_{S}=\frac{D_{M}(\Delta H)^{0.25}}{(\dot{Q})^{0.5}}
\end{array}
$$

Pump Volumetric Flow Rate Versus Pressure Rise

The pump delivered volumetric flow rate versus pressure rise for the three tests speeds is shown in figure 9. The pump flow rate, Q6ACTUAL, based on the fluid density at the pump suction port, is calculated from

$$
\dot{Q}_{\text {6actual }}=\frac{\dot{M}_{\text {6actual }}}{\rho 4}
$$

where $\dot{M}_{6 a c t u a l}$ is the pump delivered mass flow rate and is measured at the venturi flow meter. The inlet density, $\rho_{4}$, is calculated from temperature and 
pressure measurements taken near the pump suction port in the run tank. This method of calculating the volumetric flow rate was selected since the density of $\mathrm{LH}_{2}$ varies by relatively large amounts through the pump. From the data it can be noted that the flow rate decreases as pressure rise increases. This behavior is expected since the rate of leakage flow will increase with increasing pressure rise across the pump. Since the delivery curves for all three speeds are the same shape, it can also be implied from these data that the leakage flow rate is primarily a function of pressure rise across the pump and not of pump speed. Since the delivered flow rate is simply the difference between the ideal flow rate; which is constant with increasing pressure rise, and the leakage flow rate, this must be the case. Therefore, it can be seen that the leakage flow rate due to shear (where Q is insignificant in $\mathrm{LH}_{2}$.

Predicted pump flow rate, also shown in figure 9, qualitatively agrees well with the experimental data. At zero pressure rise, the theory quantitatively agrees well with the experiment, indicating that the calculated pump displacement is realistic. However, at higher values of pump pressure rise the theory is optimistic. At the design point, the predicted volumetric flow rate is approximately 5 percent higher than the experimental value. There are several possible reasons for this prediction discrepancy.

1. The assumed values of the pressure loss coefficients in the entrance regions of the leakage flow paths ( $K_{C O N T R}$ and $K_{E N T}$ ). If the assumed values of these coefficients were too high, the result would be an underprediction of leakage flow rate.

2. Uncertainty of the vane tip clearance. This is true since there is no accurate way of measuring it at this time. The tip clearance is assumed to be equal to $0.00015 \mathrm{in} .(0.0038 \mathrm{~mm})$ in the model.

3. The model now assumes that the leakage flow is laminar only. In some of the leakage paths, Reynolds numbers as high as 12000 were predicted. This indicates that there is turbulent flow in some of the paths. This error will tend to over-predict leakage flow since the turbulent friction factor, will be higher than the laminar one. It should be noted that this error alone would cause predicted flow rate to be less than the experimental values.

\section{Pump Power Consumption Versus Pressure Rise}

Experimental data, as well as theoretical predictions for pump power consumption are shown in figure 10. The power consumption is a linear function of pressure rise at a given speed with a finite amount of power consumption at zero pressure rise. This power is required to overcome vane friction and is proportional to $\mathrm{N}^{3}$. This behavior is expected and is typical of vane pumps (ref. 5).

Theoretical predictions for pump power consumption show excellent agree- . ment with the experimental data at all three speeds.. The value of the dynamic coefficient of friction in the model was adjusted to fit the experimental data and a value of 0.123 was required. This compares well with the value quoted by the manufacturer of the leaded bronze material of 0.14 under dry conditions. 


\section{Pump Delivered Mass Flow Versus Pump Speed}

Experimental data for pump delivered mass flow versus pump speed is shown in figure 11. Over the range of test speeds, the relationship between delivery and speed is a linear one. Extrapolation of the zero pressure rise line passes approximately through the origin as expected.

Since the slopes of all three curves are equal, conclusions similar to those drawn from delivery versus pressure rise data may be drawn from figure 11 (i.e., Qshear is insignificant).

\section{Torque Efficiency Versus Pressure Rise}

Experimental data for torque efficiency versus pressure rise is shown in figure 12. The experimental torque efficiency, nT is calculated from

$$
n_{T}=\frac{n_{\text {ovp }}}{n_{V}}
$$

Where novp and niv are calculated from equations.(33) and (31a) respectively. The torque efficiency, defined by equation (24), may also be thought of as

nT 1 Torque required to produce pressure rise onty for ideal mass flow rate actual torque

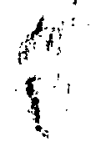

From the data, it can be seen that torque efficiency decreases as shaft speed is increased at a given pressure rise. This can be attributed to the increased vane friction which increases proportionately to $\mathrm{N}^{2}$. This effect causes an increase in actual torque thus reducing ${ }_{n}$. . Holding pump speed constant and increasing pressure rise causes the torque efficiency to increase. This is true since a larger portion of the actual torque is going to produce pressure rise.

\section{Volumetric Efficiency Versus Pressure Rise}

Figure 13 shows the experimental data for volumetric efficiency as a function of pressure rise at different pump speeds. Volumetric efficiency, nv, defined by equation (23), may be written as

$$
\begin{gathered}
\eta_{v}=\frac{\dot{Q}_{\text {Gactual }}}{\dot{Q}_{\text {ideal }}}=1-\frac{\dot{Q}_{\text {jeakage }}}{\dot{Q}_{\text {idea }}} \\
\eta_{v}=\frac{\dot{M}_{\text {Gactual }} / \rho 4}{v_{0} N}
\end{gathered}
$$


This is the equation from which the experimental volumetric efficiency was calculated. For a given pressure rise, the data shows that volumetric efficiency falls with a decrease in shaft speed. This is due to a decrease in Qideal since

$$
\dot{Q}_{\text {ideal }}=V_{D N}
$$

while Q ieakage remains essentially constant. Therefore, nv must decrease as equation (3i) shows. The data also show that volumetric efficiency falls with an increase in pressure rise at a constant pump speed. This may also be explained by equation (31). In this case, Qideal remains constant and Q leakage increases with increasing pressure rise:

Neither of these trends is surprising and they would be expected in any fluid. However, there is an effect on volumetric efficiency which may be attributed to the peculiar properties of liquid hydrogen. When pump pressure rise is zero, it would be expected that the volumetric efficiency would be 100 percent, since Qleakage is zero (i.e., no $\Delta p$ to drive $i t$ ). However, at zero pressure rise, the measured volumetric efficiency falls 1 to 2 percent short of the expected value, depending on shaft speed. This discrepancy may be attributed to the energy being added to the fluid from the work of vane friction. Since the density of liquid hydrogen is a strong function of its temperature, the density of the $\mathrm{LH}_{2}$ at the pump discharge will actually be less than the inlet density. Therefore, the delivered mass flow at zero pressure rise will be less than the ideal mass flow.

\section{Overall Pump Efficiency Versus Pressure Rise}

Experimental pump overall efficiency, novp versus pressure rise is shown in figure 14. Equation (25) defines the overall pump efficiency. For purposes of data reduction, novp is calculated as

$$
n_{\text {ovp }}=\dot{M}_{6 \text { actual }}\left[h_{6}\left(p_{6}, s_{4}\right)-h_{4}\left(p_{4}, T_{4}\right)\right] / \dot{\omega}_{\text {actual }}
$$

where the bracketed quantity is the isentropic enthalpy rise of the pumped fluid.

The overall efficiency was defined in equation (25) as the product of nT and ny: As pressure rise is increased, these two parameters tend towards opposite directions. Therefore, an optimum value of novp is expected for a given pump speed.

It can be seen from the data that novp changes little over a fairly wide pressure range. This is fortunate since it allows the pump to be operated over a range of pressures with little penalty in overall pump efficiency.

\section{Pump Life Test Results}

The vane pump was successfully operated in $\mathrm{LH}_{2}$ for $10 \mathrm{hr}$ under steadystate conditions. These conditions, as stated earlier, were a pump speed of $8000 \mathrm{rpm}(838 \mathrm{rad} / \mathrm{sec})$ and a pressure rise of $300 \mathrm{psid}(2.07 \mathrm{MPa})$. At this pump speed, the average vane tip speed was about $40 \mathrm{ft} / \mathrm{sec}(12 \mathrm{~m} / \mathrm{sec})$. The 
total accumulated operating time on the pump was $15.3 \mathrm{hr}$. with a total of 96 starts. During start-up, the pump was accelerated from rest to a speed of $8000 \mathrm{rpm}$ ( $838 \mathrm{rad} / \mathrm{sec}$ ) in about $45 \mathrm{sec}$. The discharge pressure was not allowed to build-up during the acceleration.

Pump performance was monitored during the tests and no degradation of performance was observed. After $7.94 \mathrm{hr}$ of total run time and 50 starts, the pump was disassembled and the condition of the pump hardware was documented. Care was taken so as not to disturb any of the worn material and bias the results of subsequent life tests. During the reassembly, parts were replaced in their original locations and orientations.

The pump liner showed no signs of material loss, but there appeared to be leaded bronze smeared onto the bore. However, the smearing was not of sufficient quantity to permit measurement. The rotor showed no signs of material loss or smearing in the slots or on its sides. The port plates were worn slightly; the patterns resembled the contour of the cam bore, indicating that there had been some rubbing of the vane sides. This wear was also insufficient to be measured.

The most severely worn components in the pump were the vanes. Material was lost in sufficient quantities to be detected by weight loss. The vanes were weighed in the new condition, at $7.94 \mathrm{hr}$, and at $15.3 \mathrm{hr}$. The percentage of vane material lost as a function of operating time is shown in figure 15 . At $15.3 \mathrm{hr}$, only 3 percent of the vane material had been lost. From the data, it can be see that the rate of materlal loss was roughly 0.2 percent/hr.

The area where the vanes are most severely worn is at the tips. Figure 16 is a photograph of the vane tips in the new condition. Figure 17 shows the vane tips after $7.94 \mathrm{hr}$ of operation. The vanes are shown with the leading face toward the bottom of the photographs. The wear in this area is highly polished in appearance and most severe in the locations passing under the ports in the liner. A burr may also be noted on the trailing side of the tips. Figure 18 is a photograph of the worn faces of the vanes, also taken after $7.94 \mathrm{hr}$ of operation. The top two vanes are shown with the trailing face up and the bottom two vanes are shown with the leading face up. All the vanes are shown with their tips toward the top of the photograph. The burr mentioned earlier can be seen at the tips of the top two vanes, as well as a polished area where the vanes contact the rotor slot when they are subjected to tangential pressure loading. The bottom two vanes also show some wear at their bottoms from rotor slot contact. The appearance of the hardware at $15.3 \mathrm{hr}$ was similar to that at $7.94 \mathrm{hr}$. Based on the appearance of the hardware and vane weight loss data, $15.3 \mathrm{hr}$ of pump life does not appear to be a limit. Therefore, it is reasonable to expect a much longer pump operating lifetime.

\section{SUMMARY OF CONCLUSIONS}

The vane pump performed well in liquid hydrogen, achieving an overall pump efficiency of 49 percent at the design point of $8000 \mathrm{rpm}(838 \mathrm{rad} / \mathrm{sec}$ ) shaft speed and $216 \mathrm{psid}(1.49 \mathrm{MPa})$ pressure rise. The delivered flow was $7.7 \mathrm{gpm}$, compared to a design goal of $7.8 \mathrm{gpm}$. 
The pump performance model predicted the pump power consumption well, giving excellent agreement with the experimental data. Pump delivery was predicted with good qualitative agreement and fair quantitative agreement with the data. The pump leakage flow model will require further study in order to improve prediction accuracy.

The pump was successfully operated in liquid hydrogen for a total of $15.3 \mathrm{hr}$ with no degradation in performance. For $10 \mathrm{hr}$ of this time, the pump was operated at $8000 \mathrm{rpm}(838 \mathrm{rad} / \mathrm{sec})$ pump speed and $300 \mathrm{ps}$ id (2.07 MPa) pressure rise. The average vane tip speed of about $40 \mathrm{ft} / \mathrm{sec}(12 \mathrm{~m} / \mathrm{sec})$ did not appear to be a limit. The combination of B-8 leaded bronze vanes and port plates and AISI $440 C$ stainless steel rotor and liner appears to be well-suited for the vane pump.

The combination of good performance and a reasonable operating life reported here show that it is practical to operate a vane pump in iqquid hydrogen.

\section{REFERENCES}

1. Nichols, J.F., "Study of Liquid Oxygen/Liquid Hydrogen Auxiliary Propulsion Systems for the. Space Tug," Rockwell International, Seal Beach, CA, SD75-SA-0043, June 1975, p. 126. (NASA CR-134790).

2. Gluzek, F., Mokadam, R.G., To, I.H., Stanitz, J.D., and Wollschlager, J., "Liquid Oxygen/Liquid Hydrogen Boost/Vane Pump for the Advanced Orbit Transfer Vehicle Auxillary Propulsion System," Sundstrand Corp., Rockford, IL, Sept. 1979. (NASA CR-159648).

3. Hemminger, J.A., and Ulbricht, T.E., "LOX/LH2 Vane Pump for Auxiliary Propulsion Systems," 1985 JANNAF Propulsion Meeting, Vol. 1, K.L. Strange, ed., CPIA-PUBL-425, Johns Hopkins University, MD, 1985, pp. 161-170.

4. 01son, R.M., Engineering Fluid Mechanics, Second Ed., International Textbook Co., Scranton, 1966, pp. 235-243.

5. Wilson, W.E., Positive-Displacement Pumps and Fluid Motors. Pitman Publishing Corp., New York, 1950, pp. 146-159. 
TABLE I. - MAJOR PUMP DIMENSIONS

\begin{tabular}{|l|l|l|c|}
\hline \multicolumn{1}{|c|}{ Component } & \multicolumn{1}{|c|}{ Dimension } & \multicolumn{1}{|c|}{ Inches } & Millimeters \\
\hline Cam liner & Bore major diameter & 1.166 & 29.62 \\
& Bore minor diameter & 1.067 & 27.70 \\
& Liner thickness & 0.7701 & 19.56 \\
Rotor & Diameter & 1.043 & 26.48 \\
& Thickness & 0.7698 & 19.55 \\
Clearances & Rotor/portplate & 0.0003 & 0.0076 \\
& Rotor/vane & -0.0013 & -0.033 \\
Calculated pump & & $0.2512 \mathrm{in} 3 / \mathrm{rev}$ & $4116 \mathrm{~mm}^{3} / \mathrm{rev}$ \\
volumetric \\
displacement \\
at -423
\end{tabular}

NOTE: Dimensions are given at room temperature unless otherwise noted. Dimensions are given for pump builds 19 and 21.

TABLE II. - SUMMARY OF EXPERIMENTAL PUMP PERFORMANCE

AT THE DESIGN POINT

\begin{tabular}{|l|l|l|}
\hline \multicolumn{1}{|c|}{ Parameter } & \multicolumn{1}{|c|}{ English } & \multicolumn{1}{c|}{ MKS } \\
\hline $\begin{array}{l}\text { Pump speed } \\
\text { Pressure rise } \\
\text { Volumetric flow ratea }\end{array}$ & $\begin{array}{l}8000 \mathrm{rpm} \\
216 \mathrm{psid} \\
7.7 \mathrm{gpm}\end{array}$ & $\begin{array}{l}838 \mathrm{rad} / \mathrm{sec} \\
1.49 \mathrm{MPa} \\
4.86 \times 10^{-4} \mathrm{M} 3 / \mathrm{sec}\end{array}$ \\
Specific speed & $28.6 \frac{\mathrm{rpm} \sqrt{\mathrm{gpm}}}{\mathrm{ft}^{3 / 4}}$ & $0.0105 \mathrm{dimensioniess}$ \\
& & \\
Specific diameter & $0.308 \mathrm{ft}^{5 / 4} / \sqrt{\mathrm{gpm}}$ & $15.55 \mathrm{dimensioniess}$ \\
Overali pump efficiency & 49.0 percent \\
Volumetric efficiency & 88.4 percent & \\
Torque efficiency & 55.8 percent & \\
\hline
\end{tabular}

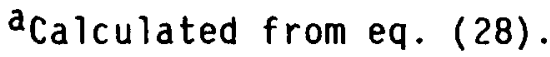




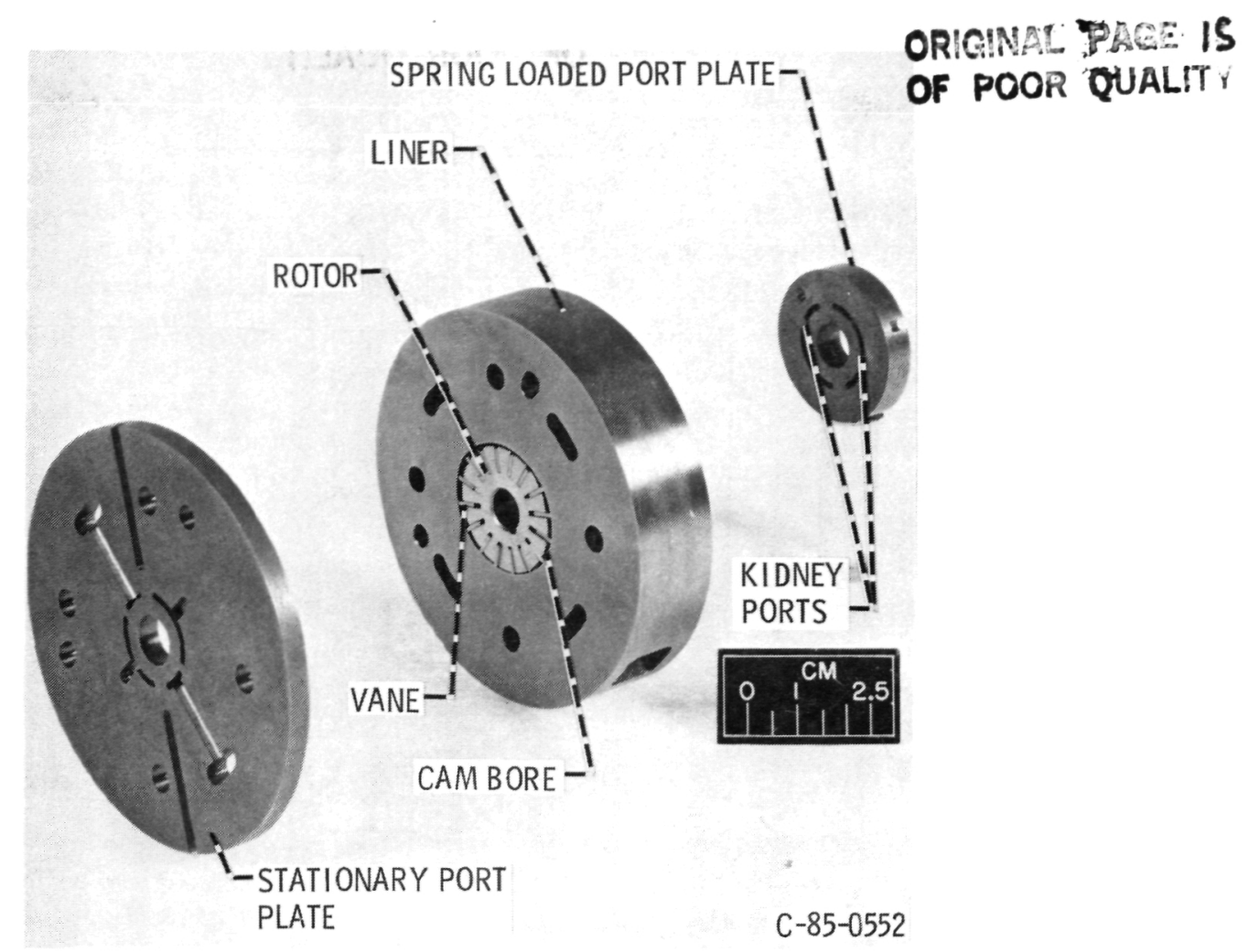

Fig. I - Vane pu mp hardware. (Exploded view)

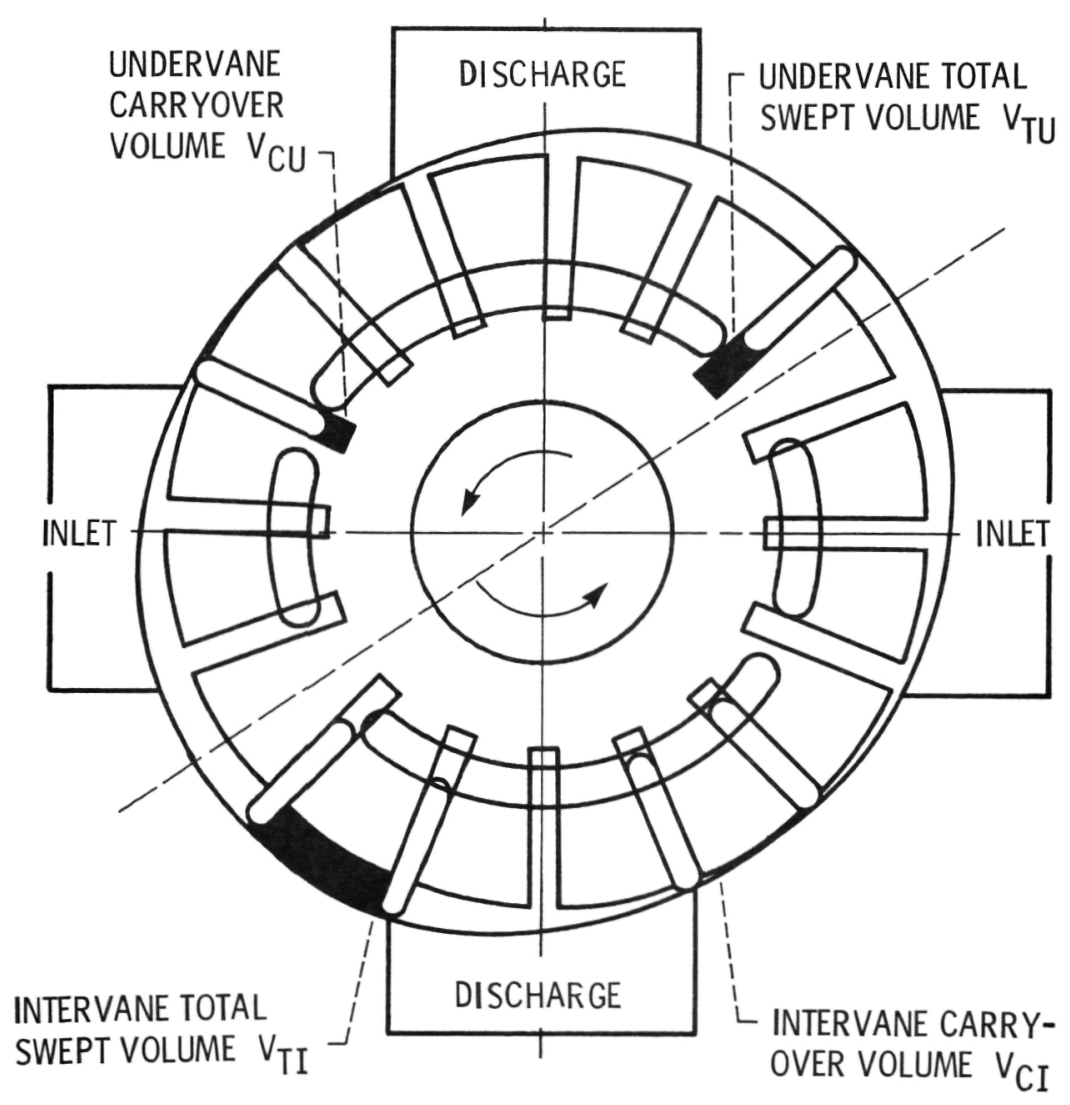

Fig. 2 - Schematic of pumped volumes. 
ORIGINAL PAES
OF POOR QUALTY

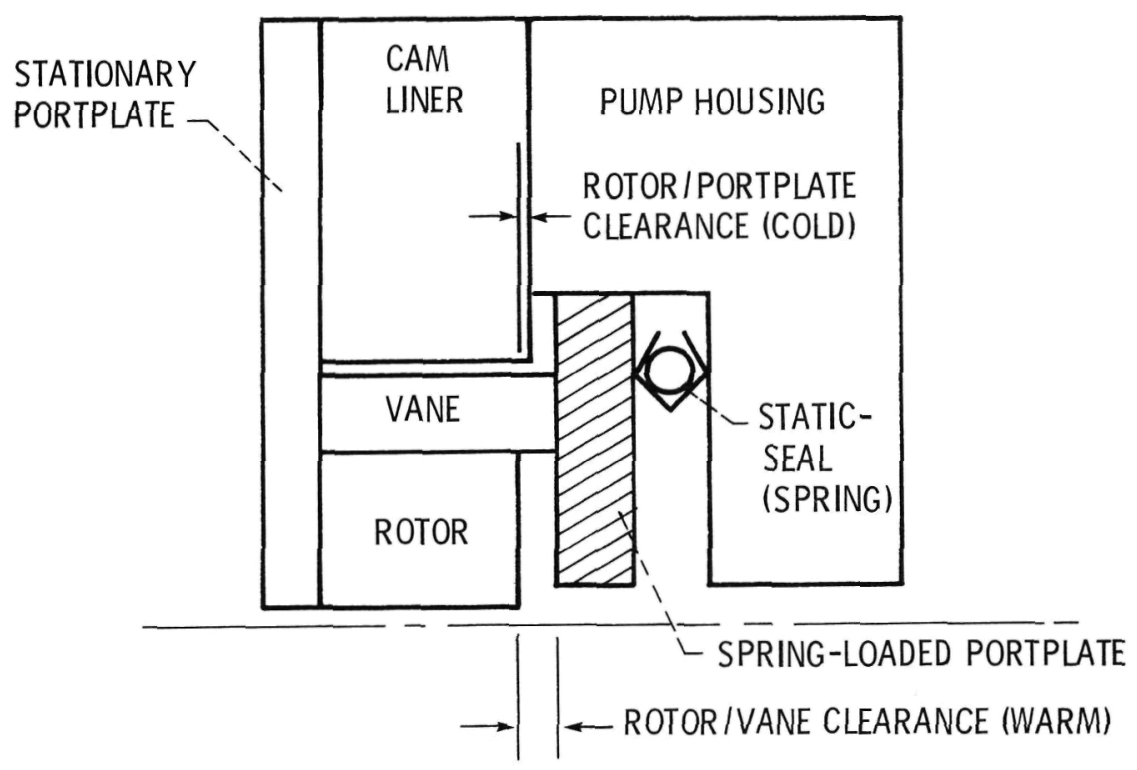

Fig. 3 - Schematic of pump clearances and spring-loaded portplate arrangement. (Not to scale; clearances exaggerated for clearness.)

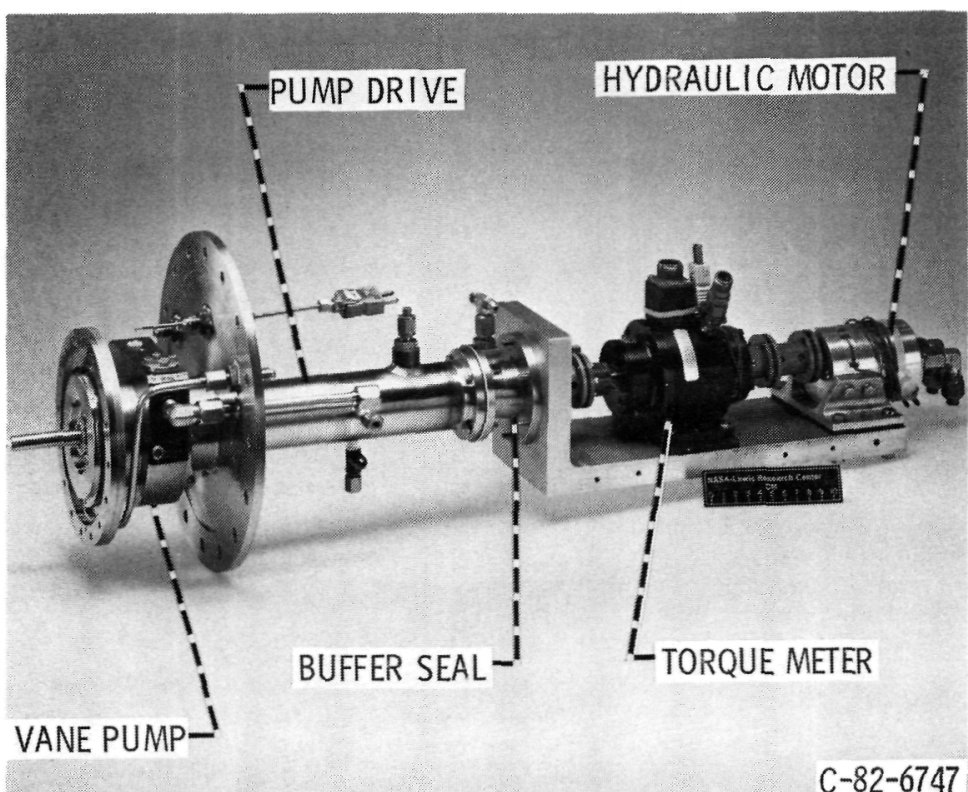

Fig. 4 - Vane pump and drive assembly. 


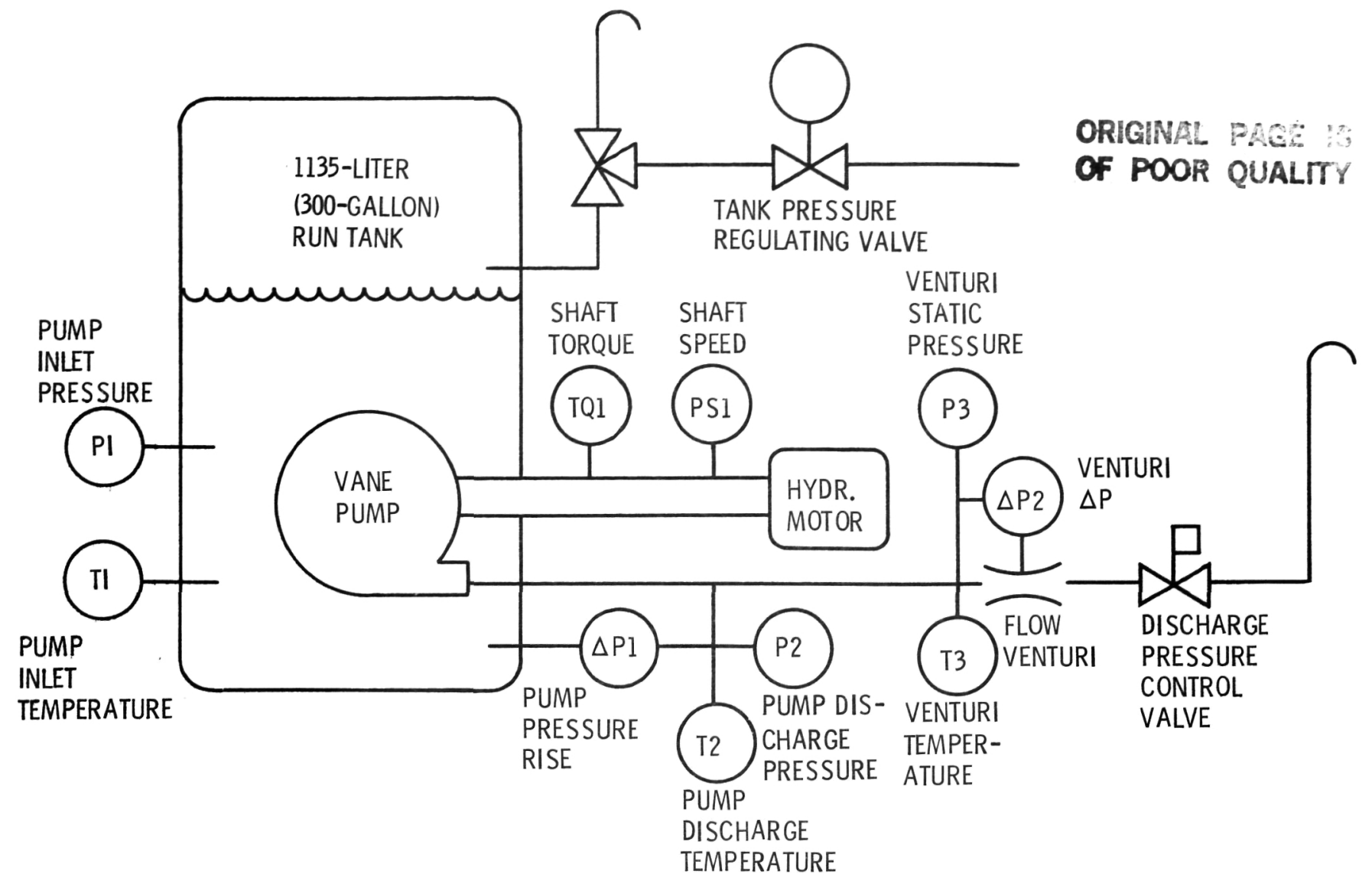

Fig. 5 - Schematic of vane pump test facility.

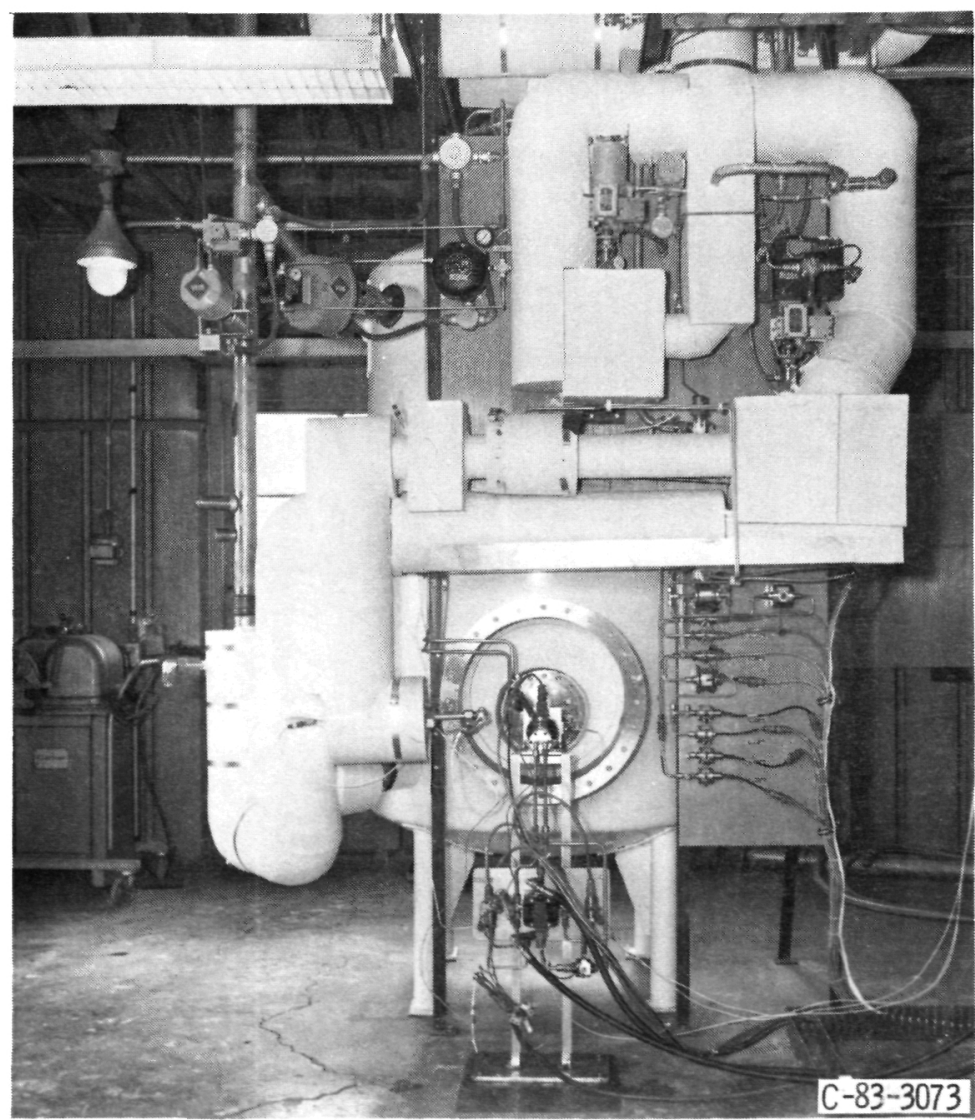

Fig. 6 - Vane pu mp test rig. 


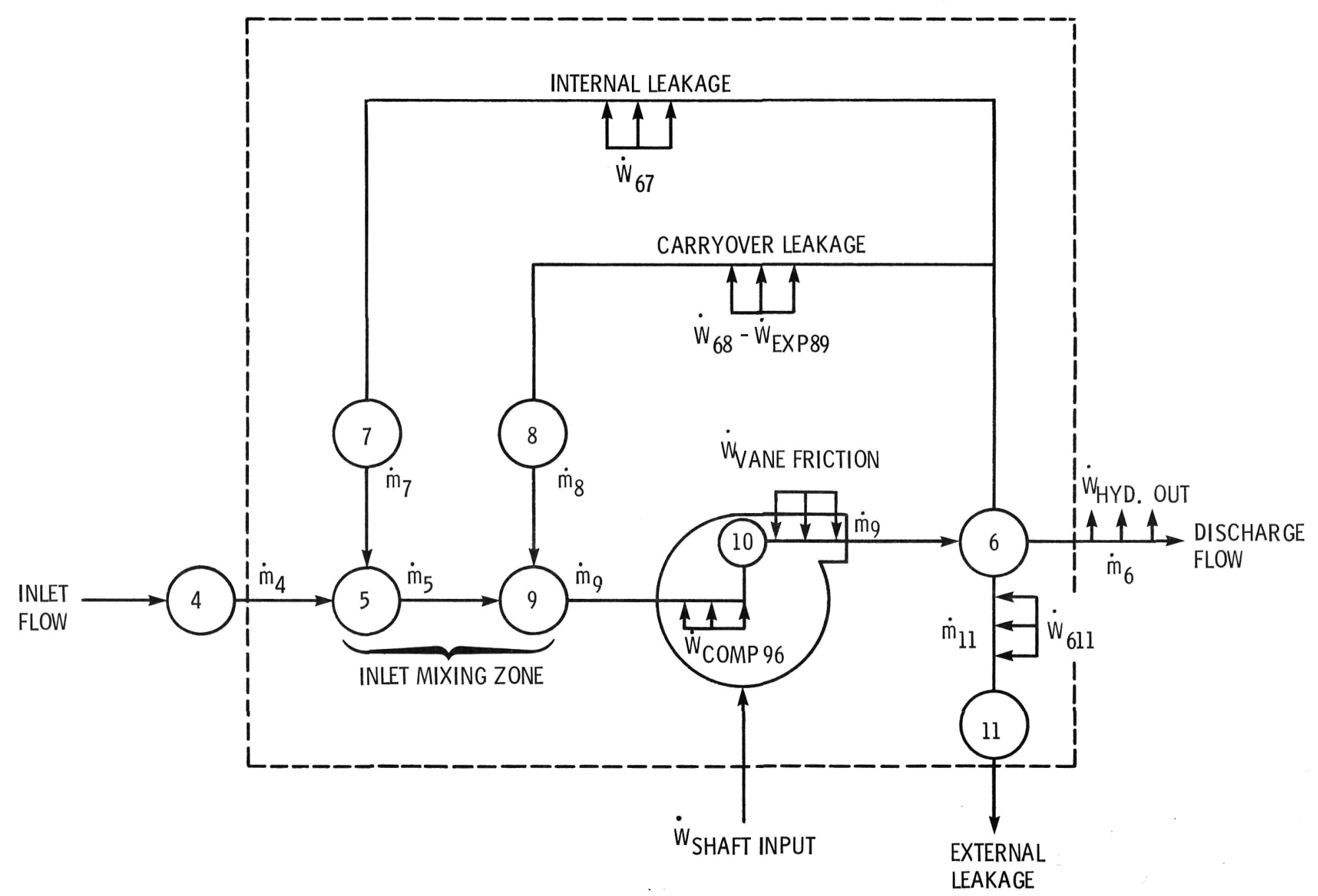

Fig. 7 - Fluid and energy flow model for vane pump. 


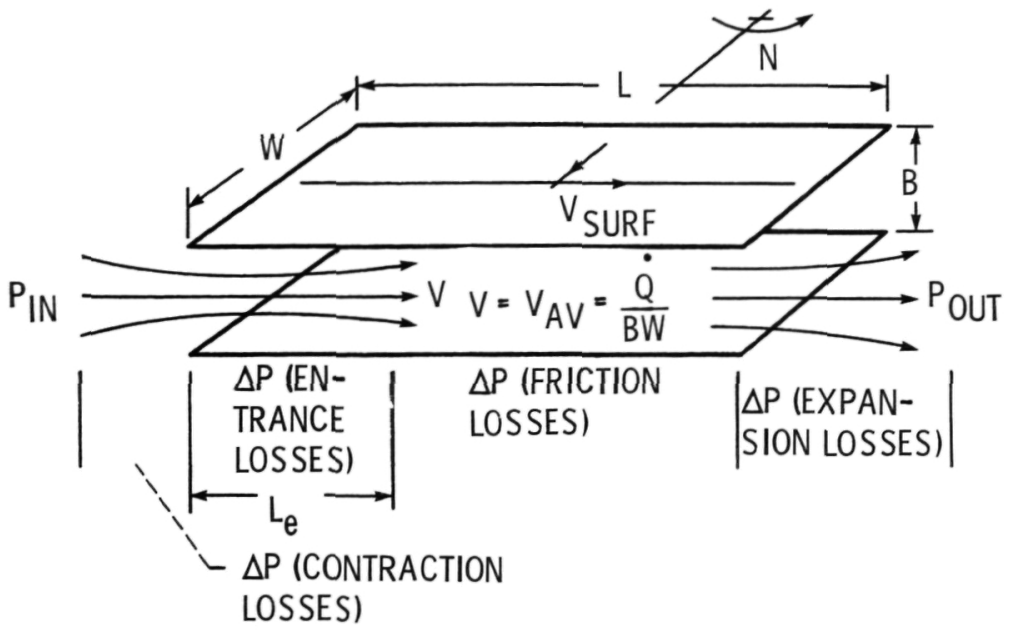

Fig. 8 - Schematic of leakage flow path.

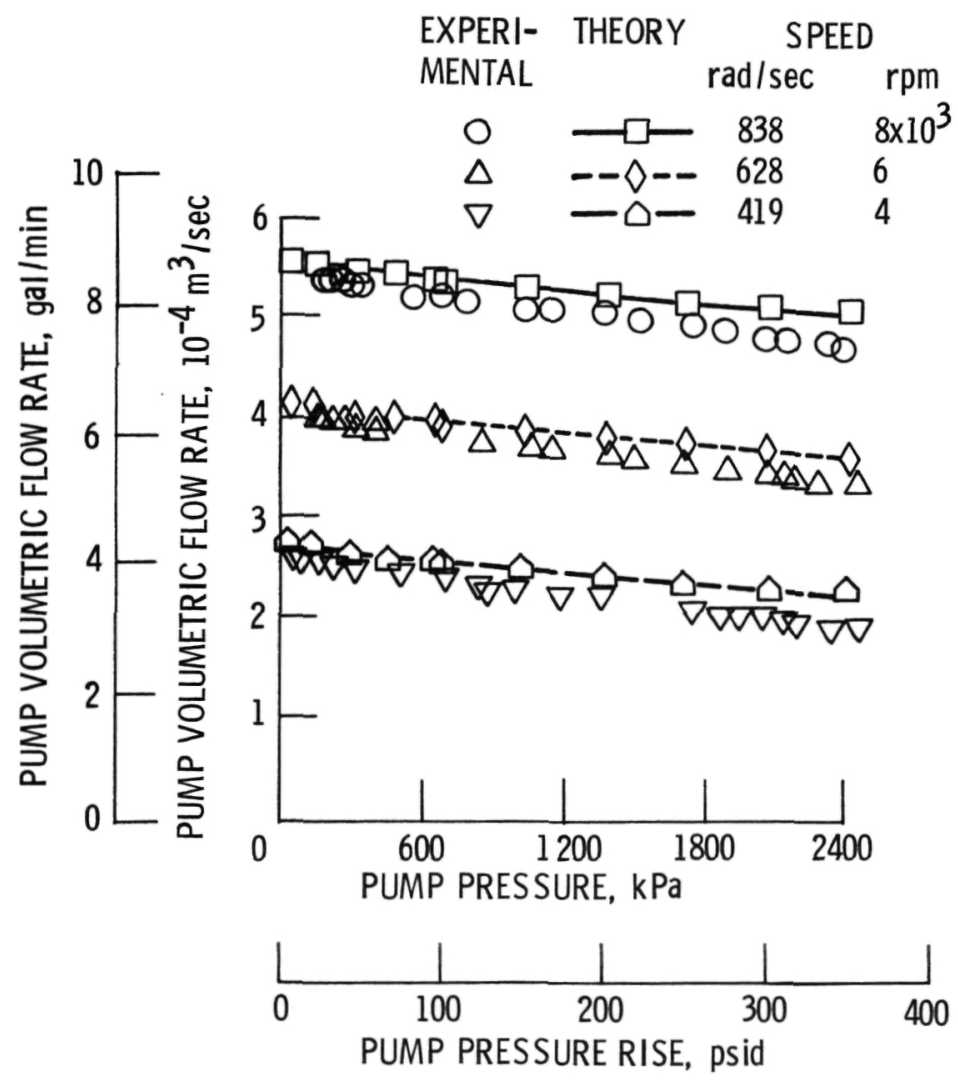

Fig. 9 - Pump volumetric flow rate versus pump pressure rise (theory and experiment). 


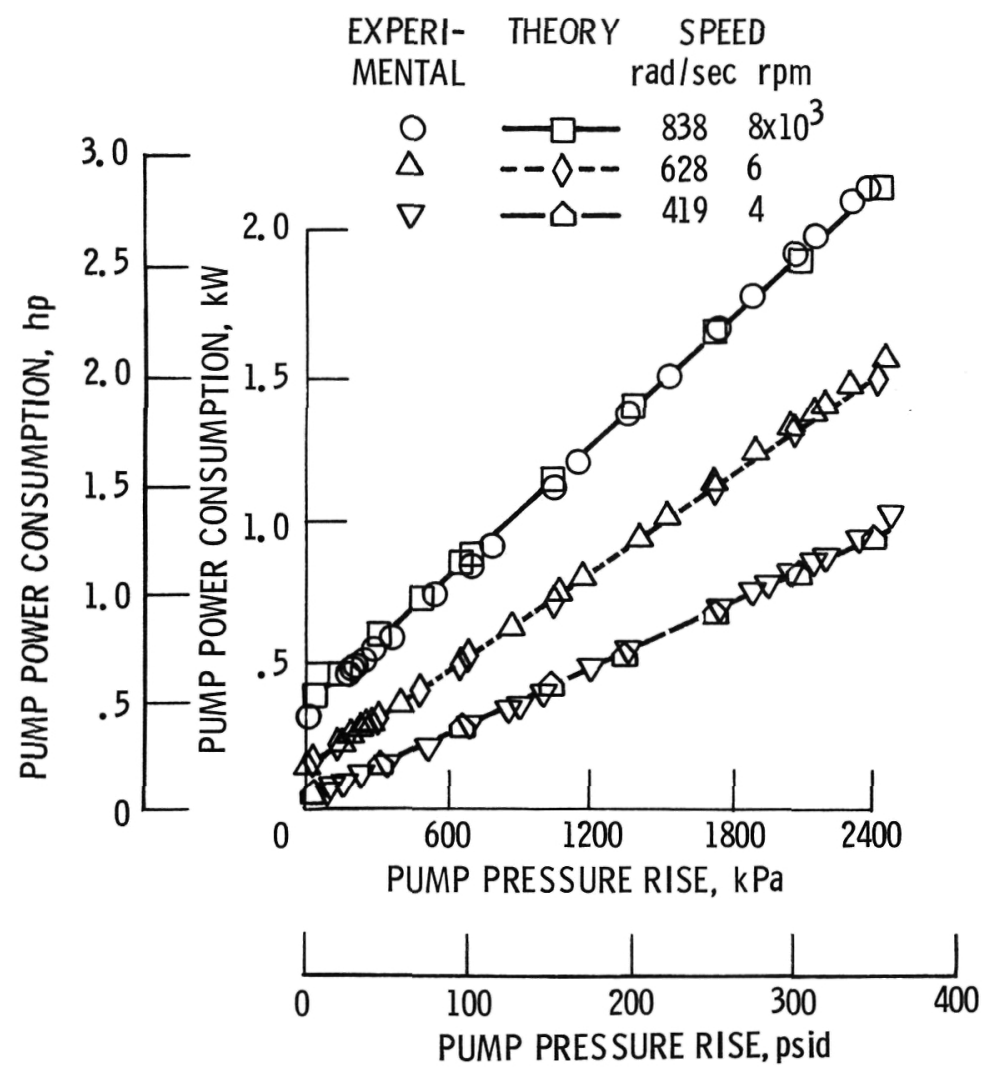

Fig. 10 - Pump power consumption versus pump pressure (theory and experiment).

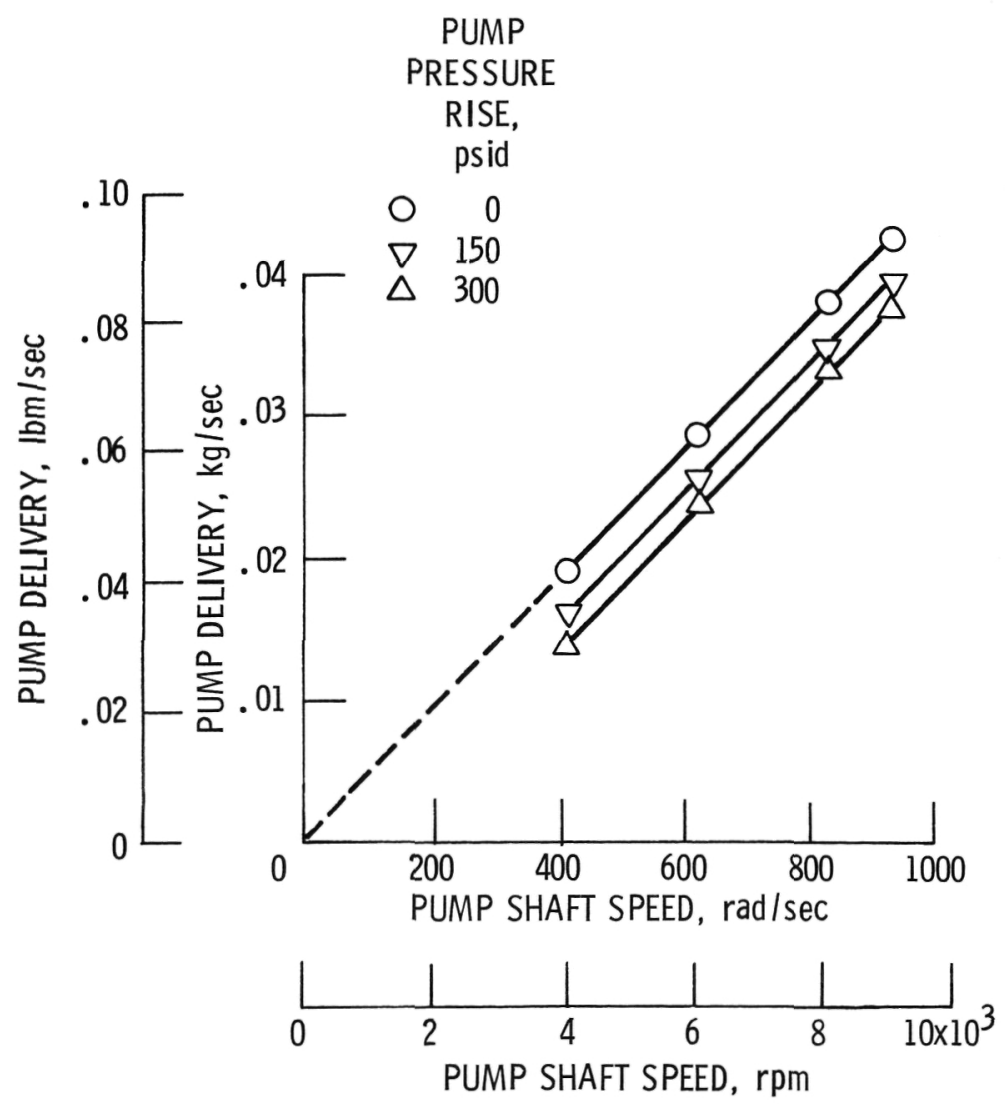

Fig. 11 - Pump delivered mass flow rate versus pump speed (experiment). 


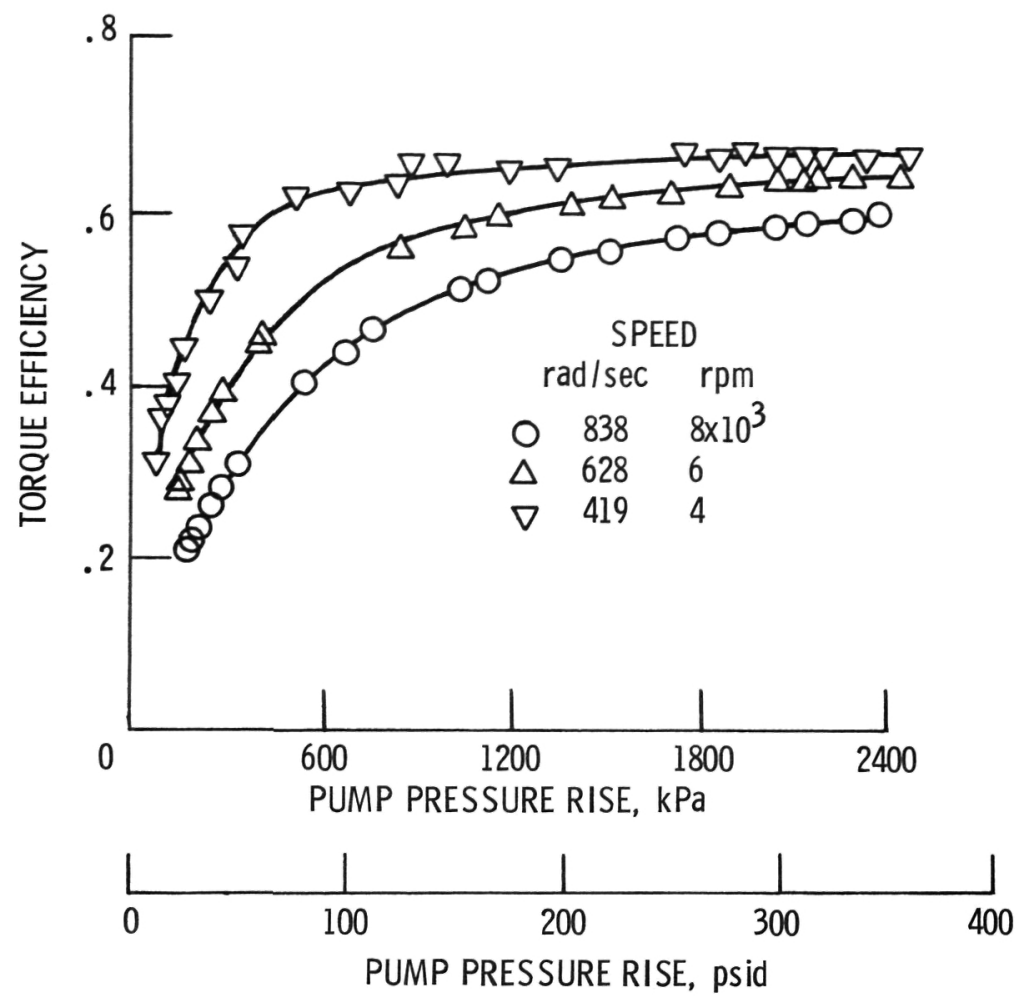

Fig. 12 - Pump torque (mechanical) efficiency versus pump pressure rise (experiment).

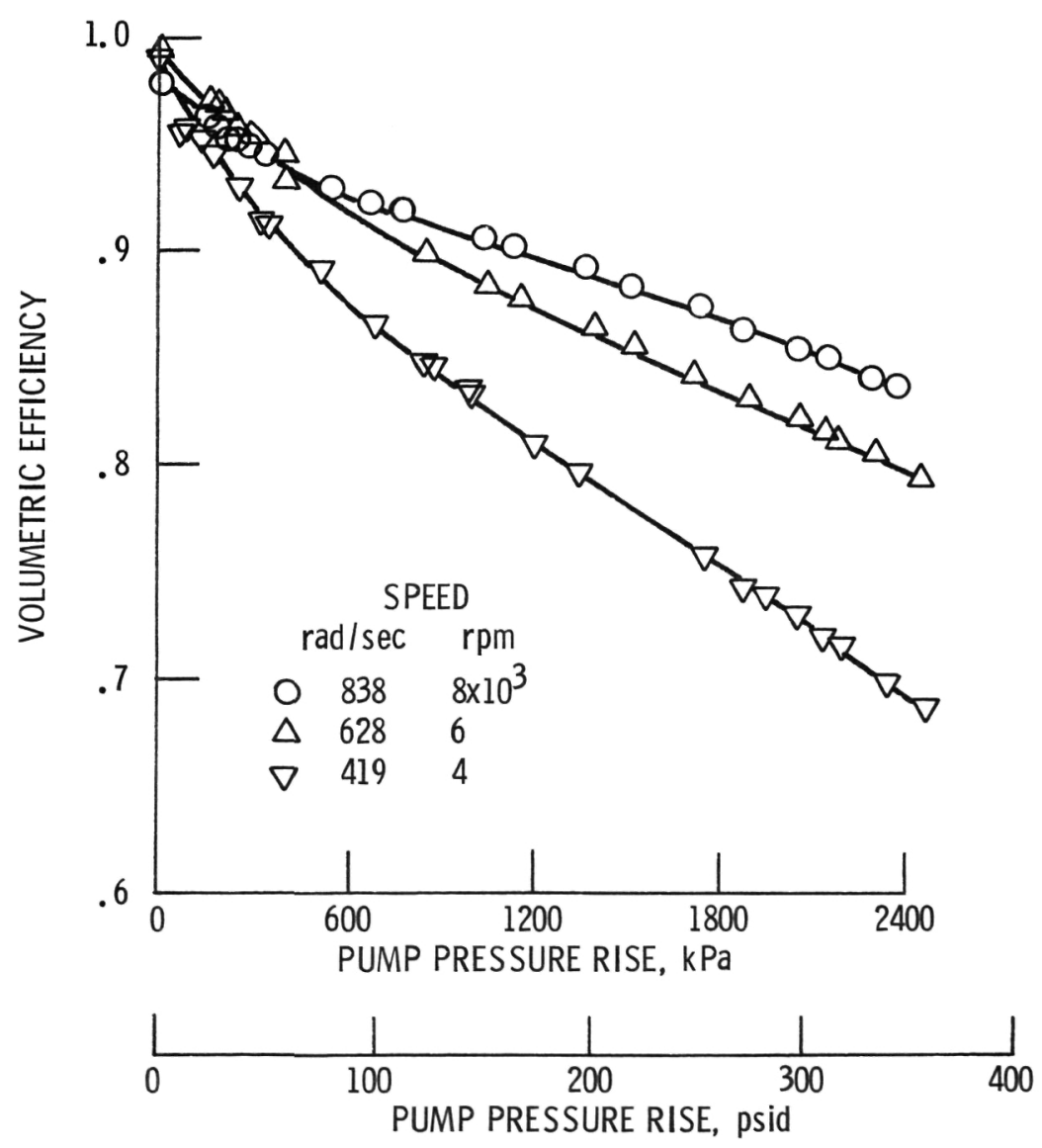

Fig. 13 - Pump volumetric efficiency versus pump pressure rise (experiment). 


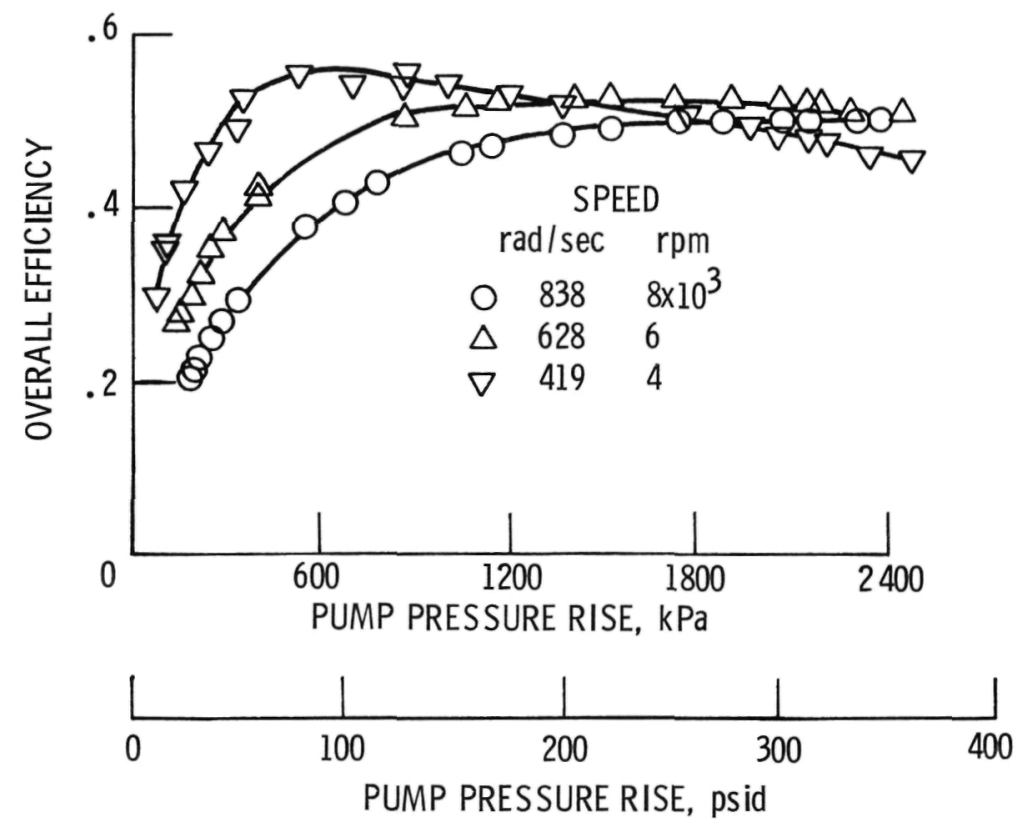

Fig. 14 - Pump overall efficiency versus pump pressure rise (experiment).

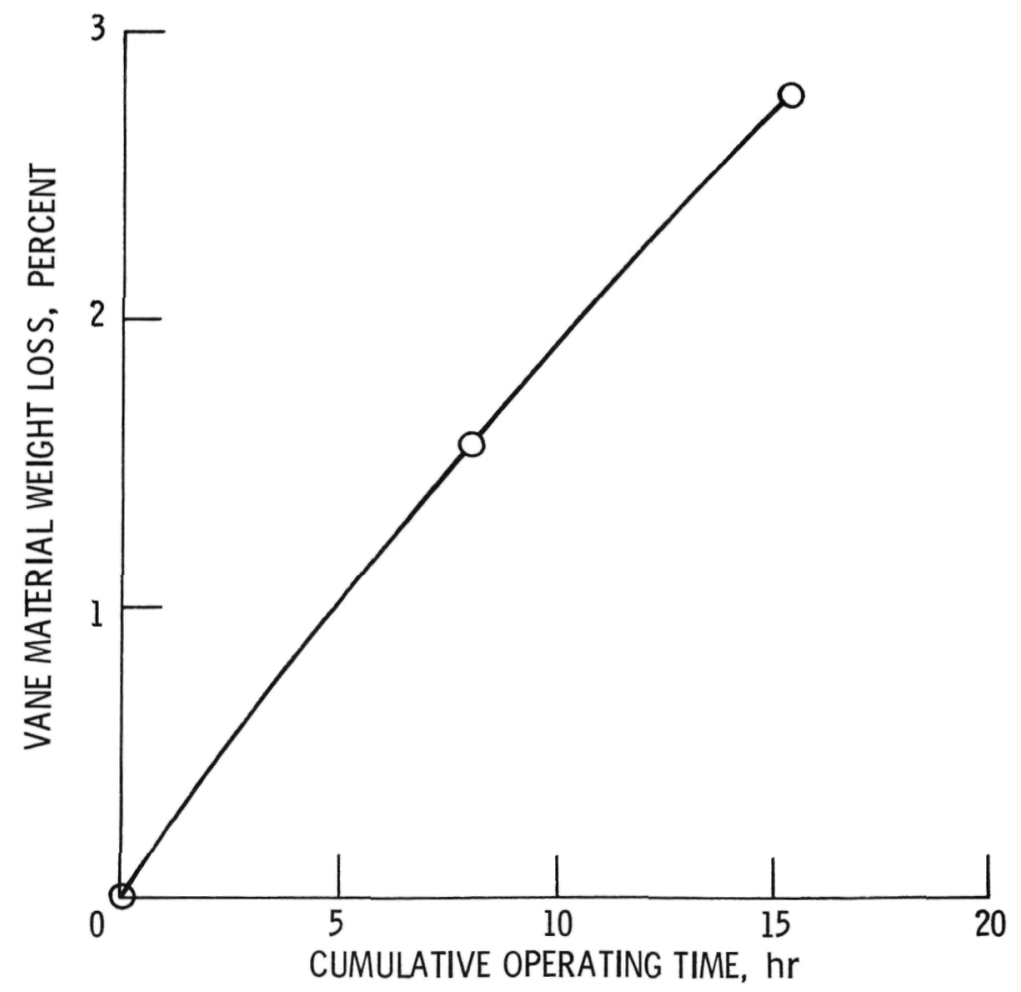

Fig. 15 - Vane material loss versus pump total operating time (experiment). 


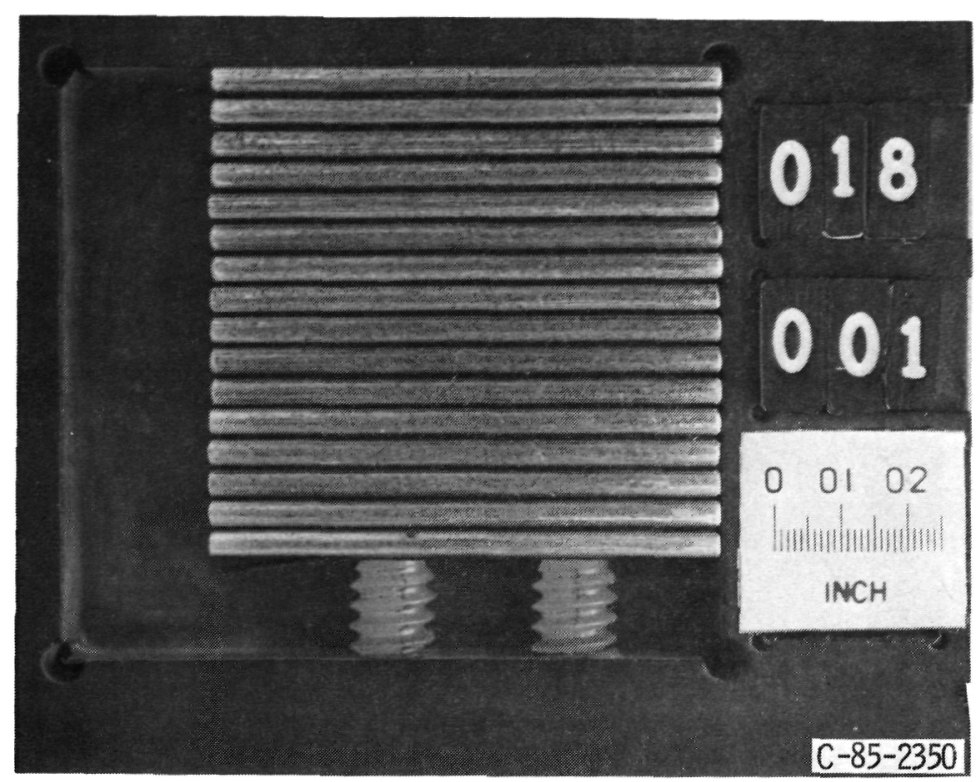

Fig. 16 - Vane tips (new).

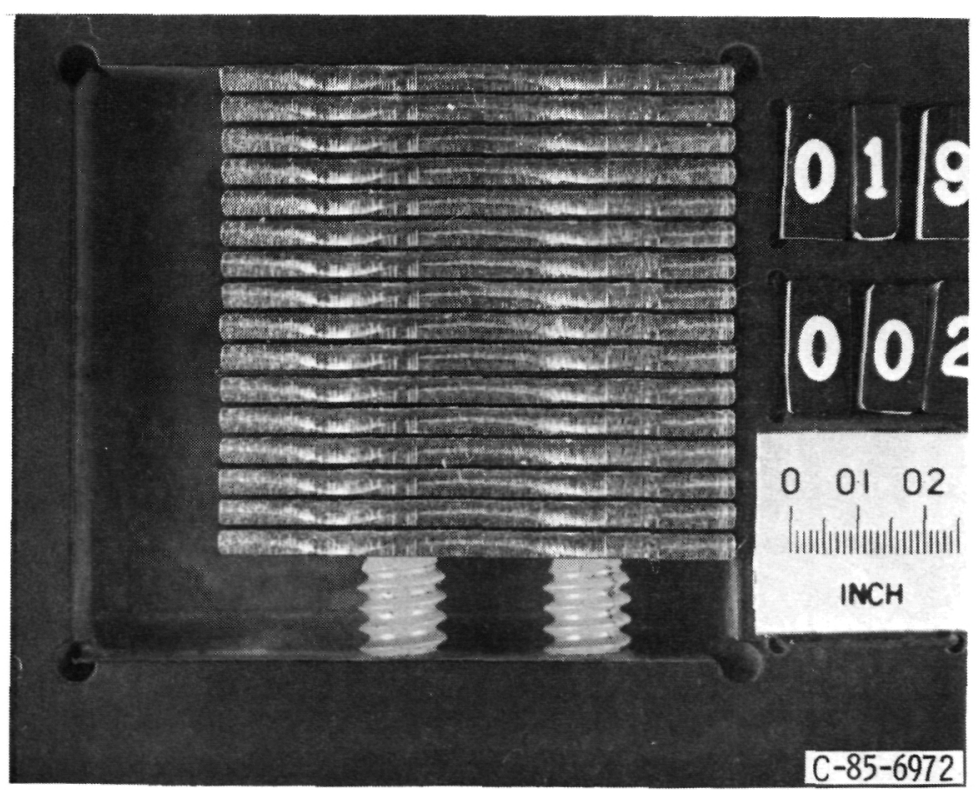

Fig. 17 - Vane tips (after $7.94 \mathrm{hr}$ of operation). 
ORIGINAL PAGE IS

OF POOR QUALITY

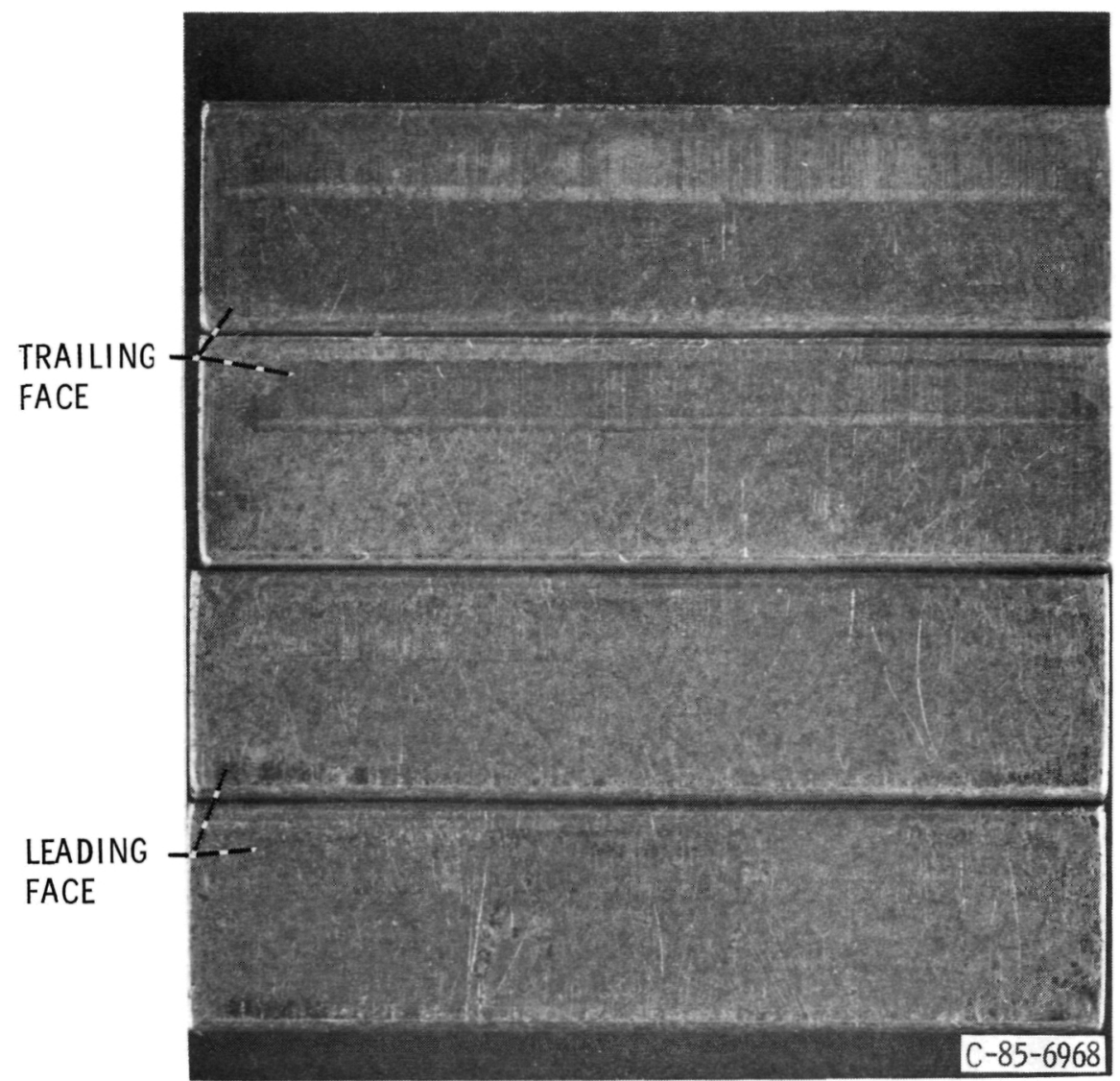

Fig. 18 - Worn vane faces. (After $7.94 \mathrm{hr}$ of operation). 


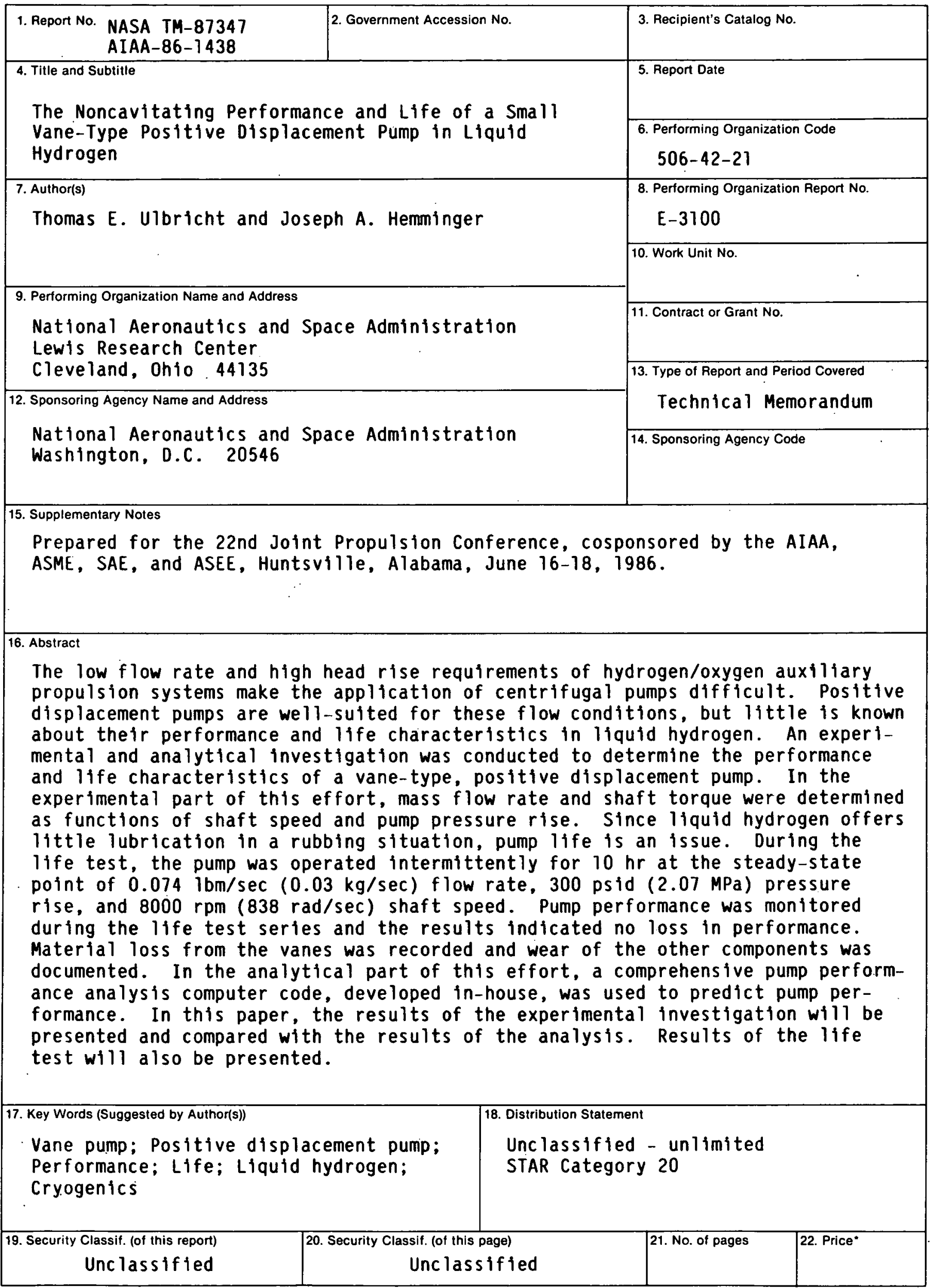

"For sale by the National Technical Information Service. Springfield, Virginia 22161 
National Aeronautics and Space Administration

Lewis Research Center

Cleveland. Ohio 44135

Onilial Business

Penaly for Pitvato Uso $\$ 300$
SECOND CLASS MAIL

ADDRESS CORRECTION REQUESTED

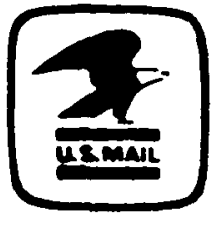

Postage and Fees Paid National Aeronautics and

Space Administration NASA-451 